Pragmatics 7:4.461-497.

International Pragmatics Association

DOI: $10.1075 /$ prag.7.4.02agh

\title{
TROPIC AGGRESSION IN THE CLINTON-DOLE PRESIDENTIAL DEBATE
}

\author{
Asif Agha
}

\section{Introduction}

This paper attempts to answer a rather basic question about the nature of linguistic aggression: How do we recognize aggression in utterances? Or, more particularly: How do we construe any given utterance-event as an instance of an 'aggressive' act? Questions like this are examples of a more general kind of question, one with which any attempt to account for utterance meaning must contend; this is because all such attempts face the problem of the relation between events and actions. Spoken utterances are acoustical events. Yet when these spoken events register as 'actions', they do so because we can ascribe a significance to them. So, the more general question is: How?

It is almost a truism to say that the construal of an event as an action occurs always from some situated perspective on the event, a perspective from which significance can be ascribed to it. Posed this way, the problem seems daunting. Yet, as I hope to show here, different perspectives on the same event do not differ randomly from each other. They can be scaled or calibrated one-to-another. The materials of the Clinton-Dole presidential debate which I consider here are very well suited for this demonstration, for reasons which will become evident below. But let me first say something about 'tropes' and why I think they are relevant to the problem of action.

The modern view of tropes and figures in language is shaped most profoundly (and, in the most unfortunate way) by the period of the decline of rhetoric into mere 'tropology' (Ricoeur 1979, ch. 2), i.e., by the attempt to classify tropes into inventories and types, ever more detailed, by giving each a distinct name. Yet this attempt has some of the qualities of a rearguard action; it is an attempt to deal with a problem by containing it, in names. Today, it seems reasonably clear that the attempt exhaustively to name and enumerate 'the tropes' of language is futile; certainly, to every inventory so far given, we are always able to add some more.

Yet the tropic qualities of language have interested everyone who has considered the problem of utterance meaning. This is partly because tropic utterances appear to have more than one meaning; they appear to be instances of more than one act. From this standpoint, the problem of 'tropes' has a natural connection to the problem of 'action': Our attempts to classify 'events' as 'actions' become mired, inevitably, in the grey areas between prototypical cases. Consider aggression. We may be glad of the pure instances of aggression that we find - for science, if not in life! - but only until we come upon cases where the aggressive qualities of an act are intertwined with something else, some quality which is the very opposite of aggression. Since such cases are routine in everyday life, the 
problem of the 'ambiguity' of events becomes a problem for the theory of action, and merges, in itself, with the problem of tropes.

This paper is about the grey areas between the prototypical cases. It is about how we can study them empirically. If my use of the word 'trope' seems a little strange at the outset, please indulge me; I think you will agree by the end that it is not so strange after all.

\section{Tropic aggression}

I use the term 'tropic aggression' in this paper to describe cases of language use where an utterance implements aggressive effects in use but where its aggressive qualities are masked or veiled in some way. My main interest is in the question of how tropic aggression is recognizable as an effect of language use. The event of language use around which I formulate my discussion is the first 1996 presidential debate between Bill Clinton and Bob Dole. The debate - which occurred in Hartford, Connecticut, on October 6 - was broadcast on national television, and subjected to intense scrutiny by the media.

Next day newspaper coverage ${ }^{1}$ provides some initial clues regarding the incidence of tropic aggression within the debate. National newspapers described the debate as 'generally civil' (WP), 'mostly cordial' (CT), as 'decorous', having a 'temperate, civilized tone' (NYT), as marked by 'personal courtesy between the two rivals' (LAT). The candidates were said to have 'clashed - politely it seemed' (WP). Dole, in particular, was said to have displayed an 'aggressive wit', often 'needling Mr. Clinton' (NYT), as posing an 'aggressive challenge to [the] president' (CT), as using the 'tactic [of] polite aggression' (WP). Clinton was described as 'unflappable' (WP), as 'calm but assertive' (NYT); 'Nothing that Mr. Dole said seemed to get under his skin,' according to the New York Times, 'although he occasionally sounded the slightest bit defensive'.

These accounts are metapragmatic descriptions which attempt to fix and formulate the pragmatics of the debate in summary form. The remarkable thing about them is that they reflect a high degree of explicit consensus about certain features of the debate. Overall, the debate is said to be marked by a degree of politeness or courtesy. Yet beneath this surface, Dole is said to be the aggressor. These two pragmatic effects are clearly at odds with each other. Although 'politeness' and 'aggression' are not mutually exclusive features of action, they are mutually opposed descriptions of acts. I will be using the term 'tropic' to describe such cases of metapragmatic tension. I will say that two pragmatic effects have a 'tropic' relationship to each other when they are distinctly reportable in contrasting metapragmatic descriptions of the same activity. ${ }^{2}$

\footnotetext{
${ }^{1}$ Newspaper coverage forms a second type of data, distinct from the primary data of utterances. I return to the relationship between the two below. Throughout my discussion, I abbreviate newspaper names as follows: The Washington Post (WP), The New York Times (NYT), the Chicago Tribune (CT), The Los Angeles Times (LAT), the Christian Science Monitor (CSM).

${ }^{2}$ This is the general form of the problem of tropes, of which the problem of metaphor is simply a special case. Thus, if someone says 'my love is a rose', this utterance can be reported in different ways. For example, (a) "He said that he loves a flower", or (b) "He said that his love is like a flower". The problem of metaphor has been posed in various ways in the literature, but the central issue is always that a single utterance permits more than one gloss, its so-called 'literal gloss', as in (a), and its so-called 'metaphoric gloss', as in (b).
} 
My main argument in this paper is that such layers of mutually contradictory effect are discernible together in the pragmatics of utterances because the semiotic devices which constitute an utterance-act involve not one, but several norms of construal. Each such norm serves as a reflexive framework for pragmatic construal during semiotic activity, allowing language users to identify pragmatic effects while the utterance is still in play. Since several norms are invoked together during usage, their effects are identifiable in a reciprocally reflexive manner during usage: The effects projected by any one semiotic norm contextualize the effects projected by every other. All the norms I consider below are wellknown, well described norms of speech. My intent here is not to propose any new norms but to show that the analysis of utterance meaning must attend to the concurrent relevance to language use of such norms as we already know language to possess. Focusing on this issue will help us see the following: Language use appears most 'ordinary' when concurrent effects are highly consistent with each other; it appears 'tropic' whenever there are incongruities between simultaneously projected effects. Indeed, I argue below that 'tropic' language is special only in the sense that its effects are shaped by an extraordinary alignment of the resources which shape 'ordinary' effects.

Cases of tropic aggression are cases where some effects of an utterance are reportable as 'aggression', but where other concurrent effects - potentially reportable as well, though not always easily from the same perspective-are inconsistent with this description. Some of the cases of 'tropic aggression' I discuss below are characterized by such extreme internal incongruity of pragmatic effects that the utterance is not explicitly reported as aggressive at all, even though it is treated implicitly by interlocutors as having aggressive effects. Let me begin, therefore, by discussing the identifiability of 'aggression' in my data, and the question of its 'reportability'.

\section{Native speaker evaluations}

Although language users are easily able to typify certain utterances as 'violent' or 'aggressive' in their effects, there is at present no pragmatic theory of utterances which accounts for this ability ${ }^{3}$. Part of the analytic problem is that the enactment of aggression

\footnotetext{
${ }^{3}$ We can appeal to perlocutionary measures of aggression, of course. We might say that an utterance is aggressive if its hearer experiences aggression; that it is 'abusive' if someone feels abused, and so on. Although perlocutionary measures of aggression are relevant to deciding that some act of aggression has occurred, they tell us nothing about the features of the utterance-act itself which implement such aggression. A second possible appeal is to the criterion of intentionality. By this criterion, an utterance is aggressive if someone has recognizably intended aggression by it. This criterion not only has the defects of the first criterion (i.e. it tells us nothing about the aggressive features of the linguistic utterance), it also creates a second problem: It requires a criterion for identifying the intentions of the utterer in order to be empirically useful. Aside from problems of circularity, the criterion of intentionality is traditionally formulated by appeal to utterance-transcendent norms, such as the Gricean maxims. Such norms not only appear implausible in cross-cultural terms, they suffer from a serious epistemological defect: They must be assumed to be 'in play' (by the linguist) independently of any feature of the utterance-act discernible by the language user. They are utterance-transcendent in just this sense. The semiotic norms which I discuss below are immanent within language use itself. The linguist knows that they are 'in play' only because their semiotic effects are manifest
} 
in language use is not narrowly identifiable with any discrete repertoire of linguistic forms - such as a syntactic construction, or a suffix, or a register of lexemes ${ }^{4}$. The problem is illustrative of a general lacuna within pragmatic theoryUsers of every human language can commit and interpret a much larger variety of pragmatic acts than the linguist can identify by appeal to discrete linguistic repertoires.

A second, more particular, problem is that current pragmatic theory lacks any clear functional criteria for identifying 'aggression' as a pragmatic effect. The lack of discrete repertoires and functional criteria go hand in hand, to a degree. In the case of better understood pragmatic categories - such as categories of tense, evidentiality, honorification, etc. - the formulation of functional criteria has traditionally relied upon the existence of discrete form repertoires. In studying the pragmatics of 'aggression', on the other hand, we cannot formulate functional criteria by taking discrete form repertoires - already somehow differentiable from the rest of the language - as our point of departure.

We can begin, nonetheless, by taking the metapragmatic ability of language users - their ability to typify utterances as 'aggressive' — as our point of departure. This is, in any case, the general point of departure for all pragmatic analysis: The linguist can identify certain features of utterance form with certain pragmatic effects only if language users provide metapragmatic evaluations-whether implicitly, or, in explicit judgments - which serve as initial criteria on form-function identification ${ }^{5}$.

The ability of language users to formulate explicit metapragmatic reports about the pragmatic effects of utterance-forms is highly constrained by the functional properties of such forms, as Silverstein has argued:

"...we can best guarantee native speaker awareness for referential, segmental, presupposing functional forms in language...The further we get from these kinds of functional elements of language, the less we can guarantee awareness on the part of native speakers - accurate metapragmatic testimony that can be taken at face value." (Silverstein 1981: 19-20; emphases added).

to language users during usage, and are reportable by them in ways predictable by the linguist (given universal constraints on the transparency of linguistic form (Silverstein 1981), discussed below).

${ }^{4}$ Most languages do have some conventional means of expressing aggression, of course. For example, English contains epithets—such as obscenities, racial slurs, etc.-whose pragmatic effects are negatively valued by social standards of linguistic etiquette. Social standards formulate these epithets as a stereotypically tabooed language of sorts, valorizing them as a lexical register of abuse. However, although the stereotypic indexical properties of these forms make them usable as conventional markers of aggression, they form only a small inventory of semiotic devices usable in this way. The acts of aggression I examine in this paper do not employ this lexical register at all.

${ }^{5}$ Even in the case of the grammaticalized indexical categories noted above (i.e., markers of 'tense', 'evidentiality' or 'honorific relationship'), the linguist inevitably uses native metapragmatic ability as a criterion for identifying forms. Minimally, the language user must treat the use of linguistic forms as involving time reference, or evidence, or respect, in order for the linguist to identify such forms as possible markers of these content dimensions. The analysis of such forms into categories of 'tense' or 'evidentiality' or 'honorific relationship', on the other hand, requires appeal to additional kinds of data, and to cross-linguistically tested hypotheses about the nature of such categories. Native metapragmatic ability is a necessary condition on the identifiability of criterial forms, not a sufficient condition on their correct analysis. 
Since language use always unites forms which are higher with forms which are lower along these functional dimensions, native testimony is, in general, unreliable ${ }^{6}$. What Silverstein has shown, however, is that the degree of such '(un)reliability' can be scaled with respect to these functional dimensions in a cross-linguistically predictive way. Features of utterance form which have higher values (on the scales of unavoidable referentiality, linear segmentability, and indexical presupposition) have a greater metapragmatic transparency (have pragmatic effects which are more reliably reportable in everyday reflection) than forms which have lower values.

In events of tropic aggression-where features of utterance form motivate the construal both of 'aggressive' effects and of their opposite(s) - we would expect such scaling to have predictive power for the kinds of explicit reports that native speakers formulate in describing the pragmatics of these events. This is exactly what we find, as I show in my discussion of the debate below: Explicit native testimony favors those pragmatic effects which are implemented by referential, localizable, and presupposing forms in utterances. In sharp contrast, the implicit metapragmatic responses of discursive interactants reveal the uptake of effects which are often inconsistent with such explicit metapragmatic reports. For example, utterances whose localizable, referential effects are reported as 'compliments' appear to have coercive effects on interlocutors; utterances whose coercive effects depend upon non-referential, non-localizable features of text structure are not reported as aggressive at all.

My criteria for identifying utterances with contrary effects within the debate depend upon perspectival differences between members of four groups of native speakers. All of them evaluate the debate; their evaluations - whether implicit responses, or explicit descriptions - are available as data. I refer to the four groups as 'interlocutors', 'audience', 'commentators', and 'viewers'.

As a discursive interaction between interlocutors, the debate involves three people: (i) Bill Clinton, the Democratic incumbent, (ii) Bob Dole, the Republican challenger, and (iii) Jim Lehrer - a television journalist — in the role of moderator. The interlocutors offer both implicit and explicit evaluations. The way in which one interlocutor treats, or responds to, an other's utterances (especially utterances in an immediately prior discursive turn) itself constitutes an implicit metapragmatic evaluation of 'what is going on'. In some cases, moreover, an interlocutor overtly describes the pragmatics of an other's utterances as well, thus formulating explicit metapragmatic judgments about utterance pragmatics.

A second set of evaluations is provided by the audience co-present in Bushnell Theatre-in Hartford, Connecticut - where the debate occurs. At various points in the debate, the audience laughs collectively, registering a type of evaluation of the pragmatics of the event. Such evaluations are completely implicit from a denotational point of view,

\footnotetext{
${ }^{6}$ In practice, therefore, the linguist must employ both types of data: (i) the 'natural' data of language use (illustrating the treatment by natives of the 'pragmatics' of forms in use), i.e., data of an implicitly metapragmatic kind; and (ii) the data of native descriptions os usage (whether unsolicited, or 'elicited') which consists of explicit metapragmatic reports of usage. Neither kind of data is sufficient for linguistic-pragmatic analysis, though the imperfection of each is, in practice, mitigated by the availability of the other. The critical point here, in practice, mitigated by the availability of the other. The critical point here, however, is that the relevance of both so-called 'natural' and so-called 'elicited' data for pragmatic analysis lies in the fact that both types of data provide the linguist with criteria on analysis based on the metapragmatic ability of language users.
} 
of course: The audible laugh tokens only index that some metapragmatic activity is occurring. Whatever judgment the audience (as a collective actor) imposes on the debate is recoverable only in a partial way, at best: It is recoverable partly from the way in which laugh tokens are co(n)textualized by the verbal activity of the interlocutors on stage, and partly from the way in which the interlocutors respond to the laughter.

A third - and much more explicit — set of metapragmatic judgments is provided by official commentators. This group consists of television reporters and political pundits, who comment on the debate immediately after it ends; it also contains journalists, editors, and columnists who describe different aspects of the debate in newspapers reports in the days which follow. I listed some of these judgments in my opening remarks. I discusses several other examples below.

The fourth set of 'judges' is the group of television viewers who are watching this debate at home. According to official estimates, this group consisted of roughly 70 million people. From a political standpoint, this is by far the most important set of 'judges', of course. Yet, we have no detailed data of any kind regarding the individual judgments of viewers, particularly their judgments regarding the moment-to-moment pragmatics of episodes within the debate. The fact that Clinton was re-elected President is a form of collective judgment, of course; yet, this judgment has an ambiguous relationship to the debate itself. A poll conducted by the Los Angeles Times explains why both parties could claim, equally reasonably, that they had won the debate: Clinton's 'approval rating' rose by $7 \%$, Dole's by $10 \%$ and, by this criterion, Dole 'wins'; Clinton's share of 'likely voters' rose by $3 \%$, Dole's by $1 \%$ so that, by this criterion, Clinton 'wins" ${ }^{\text {"7 }}$. Some additional, and rather fragmentary, evidence is provided by newspaper reports of people's opinions of the debate, largely in the form of on-the-spot interviews. I discuss the implications of these metapragmatic judgments, briefly, in the very last section of the paper.

I use the term 'aggression' metalinguistically (i.e. to describe language use) with just the same notional content that it has in its non-metalinguistic usage. One aspect of its vernacular sense is worth making explicit, however: The term 'aggression' describes a twoplace relation, i.e., a relation holding between an aggressor and someone who is aggressed upon. I will refer to the former as an origo (or source) of aggression, and the latter as the focus of aggression. The question of how - and whether - the origo and focus of aggression are identifiable in context is often critical to the way in which aggression is masked or tropically veiled within the debate ${ }^{8}$.

${ }^{7}$ Post-debate polls also show a declining viewership for presidential debates: Whereas the first presidential debate in 1992 was viewed in more than $38 \%$ of U.S. homes, the figure for 1996 is $32 \%$. The actual statistics cited in the LA Times story (which argues that 'the debate changed few minds') are as follows (LAT, X/8: A1, A19): Clinton's approval ratings rose from 55\% to $62 \%$, Dole's rose from $51 \%$ to $61 \%$; Clinton's share of 'likely voters' rose from $51 \%$ to $54 \%$, Dole's from $40 \%$ to $41 \%$. (The only clear loser was Ross Perot-whose support had fallen from $7 \%$ to $4 \%$ by the next day-simply by virtue of his exclusion from the debate itself.) Overall, Clinton led both before and after the debate, but the debate itself did not improve his overall margin in any decisive way.

${ }^{8}$ It was well known in the classical tradition of rhetoric, for example, that the variety of normtransgressive speech called 'tropic' or 'figurative' can be used to 'mask' acts of aggression, without tempering their effectiveness or force. Hence its relevance to the training of political orators. Such masking was known to enhance interactional power asymmetries by making acts of verbal aggression metalinguistically 'invisible' in enacted rhetorical genres of [other-] 'persuasion', [self-] 'refinement', [self- 
Two points of method are worth noting here. First, since I treat the problem of tropes as involving distinct - potentially contrary - metapragmatic construals, I will, from time to time, compare the metapragmatic evaluations of four different classes of social actors: interlocutors, audience, commentators, and viewers. From this standpoint, 'the Clinton-Dole debate' consists of four distinct, but linked 'events': (i) it is a discursive interaction between three interlocutors whose utterances formulate the course of the debate itself; (ii) it is a public performance for an audience, co-present with the interlocutors; (iii) it is a performance for a national television viewership; (iv) it is also reproduced, in part or whole, by official commentators in television and newspaper reports. These four classes of events differ in their participants, as well as in the semiotic devices to which participants have access ${ }^{9}$. But the semiotic phenomena which link these events to each other, and do so most consistently, are the utterances produced by the interlocutors. These form the primary material under analysis; the data of native evaluations, though critical, is a secondary order of data.

The second point of method is this: My analysis of interlocutors' utterances will proceed independently of the data of native speaker evaluations. Such a method is necessary, of course, if the goal is to show that the semiotic properties of interlocutors' utterances themselves shape differently positioned construals of them. So, it is to a discussion of these utterances, and to the semiotic norms involved in their interpretation, that I now turn.

\section{Norm and trope}

In concluding her discussion of the pragmatics of 'directives' in English, Ervin-Tripp discusses several types of tropic usages of directive statements in English — including cases of metaphor, irony, sarcasm, 'hyperpolite' rudeness, and so on. In this context, she offers the following important observation:

"If politeness were simply a meaning dimension, there would be no bad effects in

an-other-] 'identification', and the like. In such cases, the masking of aggression depends upon alignments of self and other in roles/relationships which are reportably distinct from those of aggressor and focus or aggression.

${ }^{9}$ Some individuals are linked to the debate in more than one participant role, e.g., as television viewers, and, subsequently, as newspaper readers. The differences of participation perspective are worth emphasizing, nonetheless. The semiotic phenomena to which the interlocutors have access, for example, differ sharply from those to which the television viewers have access. One big difference, for example, is that Clinton and Dole are looking at the audience during the debate, but the television viewers are not. This difference can itself become the basis of campaign strategy, as the following example shows: "As part of a drive by the Dole campaign to rattle the President, Billy R. Dale, whom Mr. Clinton dismissed from the White House travel office and who now works for Mr. Dole, was seated in the first row, facing Mr. Clinton's lectern. He... said he had been given a ticket by Mr. Dole. "It's just a pleasure to be here," Mr. Dale said before the event began. "I'm not here to shake up the President, just to see the debate.".' (NYT, X/7: B7). Clinton, as interlocutor, was aware of Dale's presence, as were the newspaper readers who read this report; the television viewers were not aware of Billy R. Dale's presence (and of any effects he may, or may not, have had upon Clinton) while they were viewing the debate. 
erring by being too polite. It is because the deviance from a norm is given a social interpretation that ingratiation can be as insulting as deviance through rudeness...A skilled speaker relies on the contrast between what is expected and what occurs as a resource for implying meaning. His ability to communicate qualitative insults, deference, anger, sarcasm, humor, intimacy and distance rests on knowledge of what the listener expects to hear and what social features cue that expectation. Thus both to interpret the pragmatic intentions of the speaker who is ambiguous, and for the development of rhetorical strategies, speakers and hearers have to have a normative reference point." (Ervin-Tripp 1976: 64)

The question of 'normative reference points' is, I would propose, a question of which norms of interpretation are necessary for construing utterances while the utterances are still in play; I will say that such norms are 'invoked' by utterances as conditions on their construal. Since particular phases of discursive interaction co(n)textualize each other, norms invoked in one phase may provide the 'reference point' for another phase, of course. But before I turn to relationships of co(n)textualization, let me say something about norms which are invoked in local phases of discursive interaction.

Since the entire debate takes place in English, the norms of English grammar are, we might say, locally invoked in every phase of the discursive interaction; they have a global provenance within the debate simply because they are invoked locally by utterances throughout. One of the ways in which utterances invoke grammatical norms is by canonically instantiating them. Many utterances within the debate are well formed by phonemic and morphosyntactic criteria; at the level of grammatico-semantic content, many utterances are canonical by criteria of sense-compositionality as well. But some of the most memorable metaphors used in the debate call attention to themselves as denotational metaphors precisely because they are not canonical with respect to sense-compositionality. For example, one of Clinton's campaign slogans, one which he uses several times in the debate, consists of the phrase 'a bridge to the future'. Since 'bridge' is a [+concrete] noun, and 'future' is [+abstract], the sense-configured relationship between these two nouns - configured by the morphosyntactic structure $\left[[\mathrm{a} X]_{\mathrm{NP}} \text { to }[\text { the } \mathrm{Y}]_{\mathrm{NP}}\right]_{\mathrm{NP}}$-is noncanonical due to the difference in semantic class of X and $\mathrm{Y}$ (compare 'a bus to the school', which is sense-canonical). Criteria of sense-compositionality-already in play, since English is in use - provide a 'normative reference point', as it were, relative to which the noun phrase itself - which conforms to these criteria in every other respect - contains an identifiable sense anomaly. The identifiability of a metaphoric utterance and its construal as a metaphor are two different things, of course. The metaphoric construal of 'a bridge to the future' depends critically on external contextualization of any utterance which contains the phrase; the fact that it is a slogan which (only) Clinton uses (in seeking re-election, in the final presidential term of the twentieth century, etc.) is critical to how the metaphor is construed here. On the other hand, the identifiability of the form as a potential metaphor - its metaphoric formulation, we might say-is motivated phrase-internally by a sequence of words which is non-canonical by sense-criteria.

A second norm of denotational construal involves the stereotypic denotation of words. Denotational stereotypes about lexemes are beliefs about the denotata of words which are consciously reportable by members of a community (Putnam 1975). Insofar as such beliefs have a social distribution (i.e. are comparably reportable by many members of 
a society) they serve as social norms in the denotational construal of utterances. Typically, however, such norms have a more restricted social distribution than norms of grammatical sense-compositionality. The latter are known implicitly by anyone who speaks the language by virtue of his or her grammatical competence. Norms of lexical stereotypy, on the other hand, are often less widespread socially, as in the characteristic case of specialized vocabularies. In the vocabulary of contemporary American political discourse, for example, the word 'Whitewater' has a stereotypic denotation quite distinct from the sense properties of the noun phrase [white water] $]_{\mathrm{NP}}$ (whose compositional sense is recoverable by every speaker of English); it is distinct, also, from the place name 'Whitewater' (as known, for example, to residents of Whitewater (Wisconsin) as the proper name of their hometown). In the vocabulary of contemporary politics, 'Whitewater' is a metonymic label for a real estate scandal involving the Clintons (derived by metonymy from a place name in Arkansas). On one occasion during the debate, Dole mentions the name 'Whitewater'-in the utterance 'I'm not talking about Whitewater now', a trope which is interesting in several ways, as I discuss below-thus invoking the scandal by stereotypic allusion, and formulating the trope by denying the mention. Any speaker of English can recognize the denotational anomaly in every sentence of the form 'I'm not talking about X now' by knowing the grammatical sense properties of all the expressions contained within it, and by knowing the values of indexical expressions like 'I' and 'now'. The tropic construal of the anomaly in Dole's utterance is lost, however, on every speaker of English who is unfamiliar with the vocabulary of American politics, and who fails to grasp the connection between the stereotypic denotation of the word 'Whitewater' and Dole's current adversary, Clinton.

Norms of grammatical sense, lexical stereotypy and grammaticalized indexicality are social norms in the sense that they are norms having a social distribution. As such, they differ from the purely emergent orderliness of text structure, e.g., its properties of 'poetic' parallelism, including the special case of text 'cohesion'. Text structure itself provides a framework for construing events of language use, a framework created only by relationships between the sign tokens which comprise the 'textual' event. When an utterance is 'entextualized' (Bauman and Briggs (1990: 73)) —or, made differentiable from its surround - utterance-internal relationships of contextualization motivate the comparability of different parts of an utterance, relative to the larger entextualized whole. The 'poetic function' of language, as Jakobson described it, is a functional principle which motivates diagrammatic value within utterances: The diagram consists solely in the comparability of co-occurring parts. Within any discursive interaction, the textuality of semiotic devices is, in general, a multi-modal textuality - as numerous studies of 'performance' have now documented (see, for example, the references in Bauman and Briggs (1990)). The debate performance with which I am concerned here exhibits such emergent frameworks for shaping pragmatic effects as well. I return to this issue in my discussion of 'cohesion' in the examples in (3), and of 'parallelism' in example (5), as well as in the sections which follow.

My purpose here is not to describe all the norms of interpretation necessary for construing the debate as such, but rather to point out some general features relevant to any understanding of the role of norms in creating and shaping the tropic effects of language use. One critical issue is this: However many semiotic norms may be invoked by utterances or utterance-fragments themselves, all the norms which are in fact invoked are concurrently 
in play within the emergent order of discourse. During usage itself, each semiotic principle (e.g. sense-compositionality, conventional indexicality, lexical stereotypy, etc.) shapes - or, as I prefer to say-projects pragmatic effects. Since all of these effects are projected together in use, such principles have effects which illuminate each other during usage; I will say that such effects are reciprocally reflexive when considered in relation to each other. Each such effect is analytically isolable in any perspective on language use which differentiates these norms from each other, and differentiates the effects of each from the effects of the others; relative to such an analysis, features of linguistic form appear to have a functionally stratified effectiveness in utterance pragmatics. Within usage itself, however, such functional strata are projected together in a concurrent fashion. From the perspective of the language user, the effects projected upon one functional stratum are evaluated relative to the effects projected upon others. As a result, anomalies along one functional stratum - such as anomalies of sense compositionality, the opaqueness of lexical allusions, the fractionation of speech-act roles (viz. 'speaker' into 'animator'/'author'/'principal' (Goffman 1981)) — are, in principle, further construable by appeal to the effects of semiotic devices concurrently in play. The traditional lore about tropic language - that it involves a 'deviation' of some type - is better understood as the 'anomaly' of effects along one functional stratum under conditions of construal where non-anomalous effects are implemented along other functional strata. The tropic formulation-although 'noncanonical' by one criterion-is made meaningful by others. Utterances which are recognized as tropes are like meaningless utterances in being anomalous in some way; they differ profoundly in being 'meaningful' under appropriate conditions of co(n)textualization.

I turn now to an analysis of the debate itself. Since the tropic construal of utterance pragmatics involves the interplay of relatively local and relatively global effects, I turn, first, to a set of metapragmatic norms which are globally in play throughout the debate. Unlike the grammatical norms discussed above, these norms are explicitly described within the debate as 'standards' of interactional behavior; they are backed by the authority of civil institutions; they are stipulated as holding for the entire debate; they differentiate the debate from ordinary discursive interaction, formulating its character as a ritual distinct from the rest of social life. These are the 'official rules' of the debate as formulated by the Commission on Presidential debates, and by the Clinton and Dole campaigns.

\section{Official rules: The sanctioned metapragmatic organization of the debate}

In his opening remarks, Lehrer describes the official rules of the debate as follows:

(1) The 'official' rules

Jim Lehrer:

...This event is sponsored by the Commission on Presidential Debates. It will last 90 minutes following a format and rules worked out by the two campaigns. There will be twominute opening and closing statements. In between, a series of questions, each having three parts: A 90 second answer, a 60 second rebuttal and a 30 second response. I will assist the candidates in adhering to those time limits with the help of a series of lights, visible to both. Under their rules, the candidates are not allowed to question each other directly. I will ask the questions. There are no limitations on the subjects. The order for everything tonight was determined by coin toss... 
These rules give Lehrer officially sanctioned control over the role of utterer of the questions, as well as the wording and topics (or topical content) of the questions. He has the authority to address a particular question to a particular candidate, to end speaking turns by candidates, but no authority to determine the order in which candidates speak. Since he formulates the questions, he is able, to some degree, to set a standard for the 'tone' of the responses. Despite the fact that Lehrer has officially sanctioned control over these variables, the candidates exert some influence as well. Dole's remarks about Clinton exert considerable influence on the wording and topics of Lehrer's questions to Clinton. Clinton attempts independently to influence the 'tone' of Dole's statements. Both candidates speak out of turn from time to time, but the number of instances is very small.

Lehrer's questions organize the question and answer period into 23 distinct episodes. Each 'episode' has the routinized structure summarized in (2).

\section{(2) Formulaic structure of each 'episode'}

(i) An explicit question by Lehrer, addressed to one candidate

(ii) An answer by that candidate (= 'initial respondent' or 'IR')

$(90$ seconds $)$

(iii) A rebuttal by the other candidate

(60 seconds)

(iv) A response by the initial respondent

(30 seconds)

Each 'episode' begins with a substantive question by Lehrer to a particular candidate, followed by the candidate's answer; such candidate is, I will say, the 'initial respondent', or IR, of the episode. The IR's answer is followed by a rebuttal by the other candidate, followed by a second response by the IR. The choice of IRs is rotated by simple alternation.

Of Lehrer's 23 explicit questions ${ }^{10}, 21$ are topically distinct. These are distinguished by roman numerals in table 1 . Two episodes - V and XIX - have the same topic, with each candidate serving in turn as initial respondent (cf. V(a) vs. V(b), XIX(a) vs. XIX(b)).

\footnotetext{
${ }^{10}$ In addition to his 'explicit questions' (which formulate the topic of the episode, and lead to the IR's answer, i.e., to turn (2.ii)), Lehrer also produces a number of 'transitional questions' as well. These are utterances which formulate transitions from turn (2.ii) to (2.iii), or from (2.iii) to (2.iv). They have the form Address term (+ time phrase) (+?) — e.g., 'Mr. President, one minute', 'Senator Dole?'. The time phrase and question intonation are optional. These utterances re-allocate speaking turns between candidates; they often count as queries about specific topics, with the topic itself presupposable from prior discourse. As the turn re-allocation pattern becomes routinized after the first few episodes, Lehrer produces such 'transitional questions' less frequently. However, his pattern of eye gaze (as well as his use of 'lights visible to each [candidate]', see (1)) continues to provide turn allocation cues to the candidates. The question which initiates episode XIX(b) is a notable exception to the general distribution of question types. The episode begins with a 'transitional question', not an 'explicit question'. I discuss this case in some detail in section 9.2.
} 
Table 1. The 'topics' and 'initial respondents' of Lehrer's questions ${ }^{11}$

\begin{tabular}{llll}
\multicolumn{1}{c}{ Topic } & IR & \multicolumn{1}{c}{ Topic } & IR \\
\hline & & & Dole \\
I. The federal government & Clinton & XIII. The Middle East & Clinton \\
II. Now vs. four years ago & Dole & XIV. The future vs. the past & Dole \\
III. Medicare & Clinton & XV. The Department of Education & Clinton \\
IV. Dole's tax-cut proposal & Dole & XVI. School choice & Dole \\
V(a) Campaign financing & Clinton & XVII. The elite & Clinton \\
V(b) Campaign financing & Dole & XVIII. Clinton's 'liberal'-ism & Dole \\
VI. Drug use & Clinton & XIX(a). Personal differences & Clinton \\
VII. Gun laws & Dole & XIX(b). Personal differences & Dole \\
VIII. Clinton's foreign policy & Clinton & XX. Views of opponent & Clinton \\
IX. U.S. troops & Dole & XXI. Keeping one's word & \\
X. Cuba & Clinton & & \\
XI. Health care reforms & Dole & & \\
XII. Iraq & Clinton & &
\end{tabular}

The structure of all 23 episodes is routinized to a very high degree along the lines noted in (2) above. The only overt departures from this routinized-and officially sanctioned - pattern of turn allocation are a dozen or so utterances which are spoken out of turn. I discuss five out-of-turn utterances for each candidate below. Overall, Dole's outof-turn utterances appear to be highly aggressive in pragmatic effect, while Clinton's appear somewhat defensive.

\section{Obvious departures from the official rules: Out-of-turn utterances}

I begin my discussion of the candidates' verbal activity by considering their out-of-turn utterances, for two main reasons. First, these are the most obvious departures from the overt rules of the debate, the most obvious pragmatic disruptions of its 'official' metapragmatic organization. Secondly, they are the least considered of the candidates' remarks, least subject to self-monitoring. As such, they provide important clues about some features of overall persona and style, features which pervade the debate as a whole. Yet, I am also concerned here with the set of concurrent semiotic cues which shape our sense of the significance of these utterances as they occur.

\subsection{Clinton's out-of-turn utterances}

Clinton's out-of-turn utterances—summarized in (3) below-exhibit several recurrent

${ }^{11}$ My summary of the 'topics' of these 21 episodes is intended only as a rough guide to these episodes. In every case, my description of the 'topic' is based on the topical NP in Lehrer's question. Thus, table 1 is, at best, a description of what topics Lehrer explicitly formulates in his queries. How the respondents formulate and reformulate 'what the topic is' is an entirely different issue, as I argue below. 
patterns. First, Clinton's utterances tend to occur during (or between) intervals in which the audience is laughing at Dole's jokes, as shown in the column on the right ${ }^{12}$ (the one exception is (3b)); this tendency suggests that Clinton is often on the defensive. Secondly, they tend to occur when Dole's kinesic activity makes Clinton its indexical focus, whether by means of held gaze or pointing (the one exception is (3a)). Both tendencies together suggest that Clinton's out-of-turn utterances are not simply defensive, they are responses to immediate pressure; they appear almost to be drawn from him. Yet, this is clearly a superimposed effect. Its degree of saliency depends upon the density with which these independently occurring patterns are aligned in some phase of discourse (as a comparison of (3c) with the other cases shows).

A third feature of Clinton's out-of-turn utterances is that they are produced when Dole's verbal activity counts as an attack. This is locally transparent in some cases - as in (3a) and (3c) - from the content of Dole's utterances, and from the audience's overlapping laughter. In (3d), Clinton's out-of-turn avowal of his friendship with Kennedy is an attempt to parry a more textually global attack on his 'liberal' views, and on his lack of judgment in his friends, and in his dealings with them (cf. 'Whitewater'); I discuss both cases below. Within (3d) itself, these two more textually global attacks are laminated together locally in Dole's final noun phrase - uttered after Clinton's interruption, and Dole's subsequent anecdote about Kennedy-i.e., in the phrase 'your liberal friends'. The case in ( $3 b)$ is different. Here, Clinton is agreeing with Dole's non-partisan proposal (an agreement invited by Dole's utterances and held gaze); he simply speaks at a point where his utterance overlaps with Lehrer's next turn.

\section{Clinton's out-of-turn utterances}

$\underline{\text { Interlocutors }}$

(a) Episode II.

Lehrer: Senator Dole, the president said in his opening statement,

'We are better off today than we were four years ago'.

"-D'you agree? ${ }^{-»}$

Dole: (3 sec.) Well, hé's better off than he was four years ago.

--> Clinton: I agree with that. That's right.

Dole: And I may be better off four years from now, butI don't know, I look at the slowest growth in the century. He inherited a growth of $4.7,4.8$ percent. Now it's down to about 2.4 percent... $\underline{\text { Audience }}$

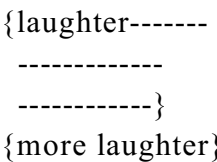

\{more laughter

(b) Episode $\mathrm{Vb}$.

Dole: ...They know the Republican party hasn't done it. They

know the Democratic party won't do it. <gaze turns to Clinton>

We have to agree that somebody else should do it, and we

\footnotetext{
12 The brackets \{\} and dashes '----' indicate approximately overlap of laughter with speech. So, in (3a), the audience's first laugh response begins after Dole has finished saying '...four years ago'; it continues right through Clinton's speech, and beyond it; after it ends, Dole begins with 'And I may...'; the audience laughs again after Dole's '...but-'; when this second stretch of laughter ends, Dole resumes with 'I don't know...'.
} 

have to vote it up or down < gaze remains on Clinton>
Lehrer: Mr. President uh, the senator men[tioned drugs...

(c) Episode IV.

Lehrer: Senator Dole, speaking of your tax plan, do you still think that's a good idea, the 15 percent across the board tax cut?

Dole: Oh yes, and you'll be eligible. <looking at Lehrer $>$ And$<$ gaze turns to Clinton $>$ so will the $=$

--> Clinton: $=$ Me too?

Dole: So will the former president $<$ points to Clinton $>$, yes.

--> Clinton: That's good $<$ sips water from a glass $>$ I need it.

Dole: Well, the people need it. That's the point.

This is not a Wall Street tax cut. This is a family tax cut. This is a Máin Street tax cut....

(d) Episode XIXb.

Dole: ...And I again- I know Senator D'Amato, I think, may have had a hearing or two on Whitewater. I can't remember. ButUh he's not my general chairman, he's a friend of mine. And- so is Senator Kennedy < gaze turns to Clinton> a friend of yours, and $=$

--> Clinton: $=$ You bet $<$ nods, smiling $>$

Dole: I remember one day on the floor I said 'Now, gentlemen, let me tax your memories,' and Kennedy jumped up and said, 'Why haven't we thought of that before,' y'know. So- so one of your liberal friends.

A fourth characteristic of Clinton's out-of-turn utterances is that they are all self-typifying statements. A first person pronoun occurs in four of them; it occurs as an overt grammatical subject in three, and is recoverable as such by text cohesion in the fourth (i.e., Clinton's 'me too? in (3c) counts, contextually, as '[Will I be eligible] too?'). Criteria of text cohesion make it clear that the fifth example (i.e., Clinton's 'you bet' in ( $3 \mathrm{~d})$ ) is, co(n)textually, a self-typifying statement as well (i.e., it counts as 'you bet [Senator Kennedy is a friend of mine]', given Dole's prior remark).

\subsection{Dole's out-of-turn utterances}

Dole's out-of-turn utterances tend to be other-typifying. Three of Dole's utterances in (4) are sentence-tokens; the fourth is the 'Oh' in (4b) (the audience is silent throughout). I discuss the fifth case in (31) below (where audience laughter becomes critical once again).

\section{(4) Dole's out-of-turn utterances}

(a) Episode Va.

Clinton: ...That's what Speaker Gingrich and Senator Dole did, not me=

--> Dole: =That's not [true, but

Clinton:

[So Í believe that we should take a different approach to this and talk about how we stand on the issues instead of trying to characterize each other's uh motivations. I think Senator Dole and I just honestly ^^-disagree ${ }^{-\wedge}$. 
(b) Episode XIII.

Lehrer: Senator Dole, on your $<$ gaze turns to Dole $>$ photo op...(1 sec.)... foreign

policy [charge against the president

--> Dole: $\quad[(()$.$) Not mine$

Lehrer: Huh? No no. I mean your charge against the président that he's [op-

Dole: $\quad[((\mathrm{Oh}))$

Lehrer: that hé has a photo op foreign policy. Does the Middle East summit last week fall into that category?

(c) Episode XII.

Clinton: Senator Dole has "--two or three times before tonight ${ }^{-» ~}$ criticized me for working wíth the U.N. Now I'm being criticized for nót working with the U.N.=

$->$ Dole: $=((\mathrm{No}))$ this is not the U.N. $=$

Clinton: =Sometimes the United States has to act alone, or at least has to act first...

All of Dole's sentence-tokens in (4) are denials; they contain grammatical markers of negation. Dole's denial in (4a) denies the truth of the proposition asserted by Clinton in his prior turn. The other two cases deny the presuppositions of a prior utterance, calling into question the appropriateness of an utterance-fragment ${ }^{13}$. All three are other-typifying negative statements.

\subsection{The significance of out-of-turn utterances}

Our ability to typify Clinton's out-of-turn utterances as 'defensive' depends upon the superposition of several semiotic cues which are independently manifest in partly overlapping phases of a multi-party discursive interaction: (i) Clinton is the indexical focus of Dole's kinesic activity, (ii) the audience is laughing at Dole's jokes, (iii) Clinton's utterances are themselves self-typifying statements, (iv) Dole's verbal activity counts as an attack. Our sense that Clinton is 'being defensive' is shaped by the superposition of these cues as they occur, though all of them do not occur in every case, nor have the same weight; nor is our sense in every case that all Clinton is being is 'defensive', though this is a salient effect in four of the cases (i.e., all except (3b)). Our sense that Dole is being 'aggressive' in his out-of-turn utterances is, equally, a superposed efect, though the number of critical cues is smaller: Dole's full utterances in (4) are all other-typifying; in particular, all of them deny the truth or appropriateness of an interlocutor's utterance. Correspondingly, our sense that Dole is being aggressive is, if anything, somewhat sharper than our sense of Clinton's defensiveness.

Each candidate's out-of-turn utterances are consistent with certain broad features of their rhetorical styles. Throughout the debate, Clinton tends to rely on self-typification more consistently than Dole does; Dole seeks to describe - and to call into question - his interlocutors more frequently than Clinton does. Yet these features of utterance style become part of a rather diverse range of overall effects during the debate, as I argue below.

\footnotetext{
13 These are denials of the presuppositions of utterance-fragments because, in (4b), Lehrer's 'your photo-op foreign policy' (which Dole interrupts) has (qua phrase) the presupposition that Dole has a photo-op policy; and, in (4c), Clinton's '...Now I'm being criticized for nót working with the U.N.' has as its presupposition that [Dole] has just criticized Clinton for not working with the U.N. In both cases, Dole denies these presuppositions.
} 
Although these out-of-turn utterances are departures from the 'official' rules of the debate, they are not, strictly speaking, violations of them. The candidates are not allowed to question each other, but there is no explicit stipulation that they cannot address or interrupt each other. The examples I consider below are, however, departures from the official rules in a more significant sense: They involve efforts by the candidates to modify the official rules- -whether through explicit formulations of additional 'unofficial' rules, or by implicit manipulation of the 'official' ones.

\section{Formulating 'unofficial' rules for self and other}

Both candidates attempt to describe the pragmatic activity of the debate by means of explicit metapragmatic statements. These descriptions explicitly typify the ongoing pragmatic enactment within the enactment itself. Such metapragmatic typifications themselves have a pragmatic effect within the enactment, of course, shaping the course of the debate as it unfolds.

\subsection{Clinton's attempts and their reception}

In the second sentence of his 'opening statement', Clinton attempts to set the tone of the debate as a whole:

(5) Clinton: $\quad$...I want to begin by saying again how much I respect Senator Dole and his record of public service, and how hard I will try to make this campaign ${ }^{\wedge}{ }^{-}$and this debate ${ }^{-\wedge}$, one of ideas, not insults..

The phrase 'and this debate' is phonetically foregrounded by a higher pitch level than the surrounding material (actually, Clinton also raises his eyebrows just as he utters this phrase, thus foregrounding it kinesically as well). The utterance is also marked by elaborate lexicogrammatical parallelism, as I show in (6) below. Framed by this parallelism, Clinton's- -characteristic- -self-typifying statements, e.g. 'I respect...', 'I will try...', etc., here achieve other-focused pragmatic effects.

Clinton's utterance in (5) begins with an explicit frame of self-report ('I want to begin by saying...'), formulating the framed material as a significant opening statement. The subsequent- -framed- -material consists of three grammatical clauses, distinguished as $\mathrm{S}_{1}$, $\mathrm{S}_{2}$ and $\mathrm{S}_{3}$ in (6).

(a) $\left[\mathrm{S} 1 \underline{\text { how }} \underline{\text { much }} \text { I respect }\left[[\text { Senator Dole }]_{\mathrm{NP}} \underline{\text { and }}[\text { his record of public service }]_{\mathrm{NP}}\right]_{\mathrm{OBJ}}\right]_{\mathrm{S}_{1}}$ and

(b) $\quad[\mathrm{S} 2 \underline{\mathrm{how}} \underline{\underline{\mathrm{hard}}}$ I will try

$$
\begin{aligned}
& {\left[_{\mathrm{S} 3} \text { to make } \quad[\text { this campaign }]_{\mathrm{NP}} \text { and }[\text { this debate }]_{\mathrm{NP}}\right]_{\mathrm{OBJ}}} \\
& \left.\left.[\text { [one of ideas }]_{\mathrm{NP}}, \underline{\text { not }}[\text { insults }]_{\mathrm{NP}} \quad\right] \mathrm{ADV} \quad \mathrm{S}_{3}\right] \mathrm{S}_{2}
\end{aligned}
$$

The pattern of self-typification continues in the italicized material: The monoclausal predicate 'respect' implements one instance of self-predication ('I respect...'), and the biclausal 'will try to make' implements two ('I will try...', '[I] make...'). In contrast to the 
simple identity of the subjects of 'respect' and 'make', the direct objects of these verbs exhibit a more layered kind of parallelism, both within and across constituents. The cumulative effect of this parallelism is to foreground the implications of Clinton's plans for 'this debate' for Dole, as I now show.

The direct object of the verb 'respect' in (a) consists of two conjoined NPs, 'Senator Dole' and 'his record of public service'; the two are linked by anaphora ('...Dole'/ 'his...') as well as by lexical cohesion ('Senator...' / '...public service'); both links jointly entail that the denotatum of the first noun phrase has a metonymic relation to that of the second (i.e., 'Senator Dole' is a metonym of 'his record of public service'). The pattern of metonymy continues within the NPs conjoined as the direct object of 'make' (since 'this debate' is part of 'this campaign'), giving way to antonymy in the NPs stacked together in the final adverbial constituent (where negation frames 'insults' as an antonym of 'ideas'). The metonyms within the direct objects of 'respect' (viz. 'Senator Dole') and 'make' (viz. 'this debate') are linked together by a higher-order metonymy: 'Senator Dole' happens to be part of 'this debate', as Clinton's adversary. Finally, the anaphoric antecedent of 'one' is the conjoined noun phrase 'this campaign and this debate'; thus, 'this debate' must contain 'ideas, not insults' as well. The latter phrase 'this debate' is phonetically foregrounded by a higher pitch level, as we have seen (cf. (5)); it is now semantically foregrounded as lying at the intersection of three metonymies (campaign/debate, Dole/debate, ideas-notinsults/debate). These metonymies locate 'this debate' rather sharply in relation to elements which are parts of it, and elements of which it is a part.

This metonymy of direct objects is overlaid by the patterning of verbs. In (a), Clinton's describes his respect for Dole (using the performative verb 'respect' in nonperformative, third person description), and in (b), he describes the rules which he himself will follow in the debate (using the factitive verb 'make' to fashion rules for himself). Given the independently motivated metonymies, these predications peformatively create a metapragmatic 'standard' for both interlocutors in 'this debate'. Notice that these alignments emerge only as the effects of current co(n)textualization: They presuppose the grammatical sense and lexical stereotypy of text-segments, of course; but they are projected as alignments only from 'poetic' co(n)textualization relationships between utterance segments. The creation of such a 'standard' is, moreover, a denotationally implicit achievement; Clinton does not explicitly ask Dole to avoid personal insults.

Yet Dole does tend to avoid explicit personal insults throughout the debate. The Washington Post describes this pragmatic effect as follows: 'The tone of the session was set early when Clinton volunteered a statement of "respect" for Dole "and his record of public service." Dole did not offer a return compliment, but he treated the "character issue," which many Republicans regard as Clinton's greatest vulnerability, with great circumspection.' (X/7/96:A1). The tropic qualities of Clinton's overall achievement becomes most evident when we compare the difference in the responses of his comentators and his interlocutor: Clinton's description of his respect for Dole has pragmatic effects which are reportable as a 'compliment' in post-debate commentary; yet, the implicit framing of this 'compliment' by textual parallelism appears to have other-coercive effects, shaping Dole's behavior within the debate itself ${ }^{14}$.

\footnotetext{
14 The effectiveness of this tropic utterance is not merely a result of the fact that Clinton utters it within the debate. Its effectiveness indexically presupposes a national discussion of (i) the 'negative campaigning' issue (in both the Clinton and Dole campaigns), as well as of (ii) Republican attempts to
} 


\subsection{Dole's attempts and their reception}

Dole's metapragmatic descriptions of his own pragmatic activity differ from Clinton's in several ways. Whenever Dole describes his own respect for Clinton, he explicitly frames the description with negative descriptions of Clinton, both before and afterwards. The following example occurs right after Dole has characterized Clinton's tax increase as 'the largest tax increase in the history of the world' (episode Va). Immediately after this charge, Dole says:

(7) Dole:

...And it seems to me that uh there's a problem there Mr. President. And I will address you as Mr. President ...(0.5 sec.)...You didn't do that with Mr.- with President Bush in 1992. (Va)

After addressing Clinton as 'Mr. President', Dole formulates a metapragmatic standard for his own address practices: 'I will address you as Mr. President'. Dole follows this up with an other-typification, faulting Clinton for not extending the same courtesy to Bush; but in doing so, Dole addresses Clinton as 'you', apparently failing to follow the rule which he has laid down for himself ${ }^{15}$. Moreover, in faulting Clinton's address practices, Dole falters in his choice of appropriately respectful titles in referring to Bush. The inconsistency between metapragmatic typification and pragmatic enactment is characteristic of Dole's utterances throughout the debate, and I discuss several examples in the next section.

I want to focus here on the differences between Clinton's and Dole's metapragmatic practices in describing the 'rules' of their own pragmatic activity. Whereas Clinton uses self-descriptions to motivate other-behavior, Dole employs self-descriptions to motivate other-descriptions. Secondly, Dole's other-descriptions are explicit criticisms of Clinton, and are reported as such by the Media:

\footnotetext{
'There were five or six lines, according to Dole aides, that they had heard him utter during the rehearsals and were hoping he would find ways to use tonight. How would he show that he honored the presidency while attacking the president? Dole allowed himself that opening by making a comparison with Clinton's treatment of President Bush. "I will address you as Mr. President," he said. "You didn't do that with President Bush in 1992." The NBC focus group thought that line in
}

formulate the 'character issue'-i.e. the issue of Clinton's character-as a major campaign theme. Clinton's achievement here aligns with both issues, defusing the first to some degree (at least for the Clinton camp) while averting an overt re-enactment of the second (by Dole). The trope aligns itself with the historical conditions of its utterance, reshaping them in some measure.

${ }^{15}$ Given the absence of any honorific distinction in English pronominal address, this usage is, of course, an unmarked choice. It is only foregrounded here by the rule which Dole has laid down for himself. Moreover, the candidates do avail of a higher register of pronominal address during the debate. This is the pattern 'Title (+ Last name) + you' (e.g., Clinton: 'Secondly, Senator Dole, you voted against the crime bill that...' (episode VI). In the third sentence in (7), Dole does not address Clinton as 'Mr. President, you...', but simply as 'You...' (the immediately preceding token of 'Mr. President' in the second sentence counts as a mention, not a use). In fact, throughout the debate, in cases where the two candidates address each other with second person pronouns, Clinton employs the 'TLN + you' construction in a much higher proportion of utterances than does Dole. 
particular was far too harsh.' (WP, X/7:A7; emphases added).

The newspaper report describes this event as an example of Dole's 'attacking the president' by appealing to the fact that Dole is 'making a comparison'. Dole's 'comparison' consists of a series of parallelistic contrasts between segmentable pieces of his self-typifying and other-typifying statements- -contrasts between subject nouns ('I': 'You'), time reference (present tense-[1996]: Past tense-'in 1992'), reported addressee ('you': 'President Bush'), and address forms ('Mr. President': '[not] that'). Although Dole employs parallelism as a rhetorical device in (7) (just as Clinton has in (5)) Dole's utterance is reportable as an 'attack' because it culminates in a denotationally transparent negative description of his opponent (and Clinton's does not) ${ }^{16}$.

Dole employs this denotationally transparent trope on one other occasion as well (episode XX). The occasion is provided by Lehrer question in (9) below; I have separated Dole's response into the segments (a)-(e), in order to isolate several interlocking themes.

(9)

Lehrer:

Dole: (a)

Senator Dole, if you could single out one thing that you would like for the voters to have in their mind about President Clinton on a policy matter or a personal matter, what would it be? Something to know about him, understand it and appreciate it.

See if I say anything, it's going to be misconstrued...(3.5 sec.)... I don't think there's even a race between the two- it's about our vision for America.

I happen to like President Clinton personally. I am addressing him all evening as $\underline{\mathrm{Mr}}$.

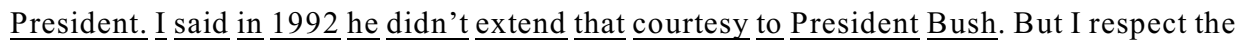
presidency.

I have served under a number of presidents. They all have their strengths, and they all have their weaknesses...(1.5 sec.)... So I'd rather talk about my strengths. I think I have my strengths.

And I think the best thing going for Bob Dole is that Bob Dole keeps his word. It's a question between trust and fear.

And I would say, I think...(1.5 sec.)... Mr. President $<$ Dole clears his throat $>\underline{\text { About all }}$ you've got going in this campaign is fear. (episode XX)

In his question, Lehrer has prescribed Dole's views about Clinton as the topic for Dole's comments. After expressing some hesitation, Dole attempts a topic shift in (a) — shifting to 'our vision for America'- but returns to the topic prescribed by Lehrer in (b). However, although he begins segment (b) by claiming to like Clinton 'personally', his typification of his own address practices in (b) only provides evidence for his respect for the 'presidency', a point which he makes explicit in the final sentence of (b); at the same time, his contrastive typification of Clinton's lack of 'courtesy' to Bush implies that Clinton - although the current president - is not respectful towards the presidency. In (c), Dole raises the issue of the strengths and weaknesses of presidents (as individuals distinct from their office) shifting thereafter to the question of his own strengths as an individual.

\footnotetext{
${ }^{16}$ It is worth noting, also, that although the Washington Post reports this as an instance of Dole's aggression by reproducing Dole's two utterances, the newspaper report does not faithfully reproduce Dole's second utterance. Dole's second utterance is actually 'You didn't do that with Mr.-President Bush in 1992'; the Post reproduces it as "You didn't do that with President Bush in 1992". The report glosses over the infelicity - and repair - in Dole's attempt to formulate respect reference to Bush. I return to the question of the reportability of metapragmatic-pragmatic inconsistency in section 9.3 .
} 
In (d), he characterizes his greatest strength as being that 'Bob Dole keeps his word'. This self-typification now motivates a contrast between '[Dole's] trust [-worthiness]' and '[whose?] fear [-mongering]'. In (e), Dole describes Clinton explicitly as the person who spreads fear, while addressing him directly.

I now list, and summarize, the four cases where Dole's self-typifications motivate other-typifications. The first and the fourth of these cases involve explicit descriptions of Clinton, while the second and the third rely on implicit framing effects: (i) Dole describes himself as respectful to Clinton, but describes Clinton as disrespectful towards Bush; (ii) framed by this contrast, the conjunction 'But' in the self-description 'But I respect the presidency' implies that Clinton does not; (iii) in the now established frame of self-andother differentiation, Dole's self-typification that 'Bob Dole keeps his word' implies that Clinton does not keep his word, without Dole's explicitly saying so; (iv) Dole describes the campaign as a contest between 'trust' and 'fear', then describes Clinton explicitly as fearmongerer.

Even a cursory glance at the material in (9) should, now, make the following points reasonably clear. First - and leaving aside the underlined material (which is denotationally transparent as aggression) - most of Dole's utterances convey a surplus of meaning beyond explicit denotation, and appear construable as 'aggressive' in some way. Secondly, the exercise of naming and counting them is quite fruitless, since the more carefully we look at the data, the number and variety of seemingly tropic acts of aggression grows. Third, if we consider the concurrent relevance to construal of the lexico-grammatical properties of text, of the indexical categories which are instantiated in it, and of the cumulative patterning of textual devices themselves, we can explain why we construe them as we do, in every case, without any problems. So, if tropes do pervade our data (and they certainly seem to) we can explain how we construe them without arbitrary assumptions, even if we need an arbitrary number of names to serve as labels. So, let me now introduce another ad hoc label for a trope (let's call it the trope of 'voiced agency in questions') whose workings are just as systematic as the cases discussed above, though ultimately more interesting - since officially, at least, the questions in our 'debate' are supposed to be Lehrer's.

\section{Breaking 'official’ rules: Formulating Lehrer's questions}

Although Lehrer is the animator (or utterer) of the explicit questions which initiate each episode, he is not always their author. On several occasions, the questions which Lehrer directs to Clinton are questions which Dole has raised (about Clinton's policies or character) in the previous episode. In such cases, Dole is the author-in some cases, the coauthor-of the questions which issue from Lehrer's mouth.

\subsection{Lehrer's questions}

Lehrer's questions may be grouped into three broad categories. The first type of question introduces a major election 'issue' (e.g. the size of the federal government, Medicare, gun laws, the Middle East, etc.) as the topic to be commented upon. Each of these topics has 
been discussed extensively by both candidates prior to the debate, as well as by the media. This is partly what constitutes them as 'the issues'. I give two examples in (10).

\section{Type 1: Questions about the 'issues'}

(a) Lehrer: $\quad$ Back to foreign affairs uh for a moment uh Mr. President. Are you satisfied with the way you handled this last Iraq crisis and the end result? (XII)

(b) Lehrer: $\quad$ Senator Dole, do you still favor eliminating the Department of Education? (XV)

In a second type of question, Lehrer formulates the question topic by quoting statements made by the candidates prior to the debate. Five of Lehrer's 23 questions are clear instances of this type. One case has already been noted in (4b) above. The other four cases are given in (11).

(11) Type 2: Questions about the candidates' prior speeches ${ }^{17}$

(a) Lehrer: $\quad$ Senator Dole, at the Republican convention, you said the following, and I quote: 'It is demeaning to the nation, that within the Clinton administration, a corps of the elite who never grew up, never did anything real, never sacrificed, never suffered, and never learned, should have the power to fund with your earnings, their dubious and self-serving schemes,' end quote. Whom precisely and what precisely did you have in mind? (XVII)

(b) Lehrer: $\quad$ Mr. President uh in your acceptance speech in Chicago...(1 sec.)...you said the real choice in this race is, quote: 'whether we build a bridge to the future, or a bridge to the past. About whether we believe our best days are still out there, or our best days are behind us. About whether we want a country of people all working together, or one where you're on your own,' end quote. Are you saying that you believe Senator Dole is a man of the past, leadand if- if elected president he would lead the country backwards? (XIV)

(c) Lehrer: $\quad$ Mr. President uh, Senator Dole has come pretty close in the last few days of accusing you of ${ }^{\wedge}-$ lying $^{-\wedge}$ about his position on Medicare reform. Have you done so? (III)

(d) Lehrer: $\quad$ Mr. President, Senator Dole said the other day that you practiced a ${ }^{\wedge}{ }^{-}$photo op op ${ }^{-\wedge}$ foreign policy that has lessened the credibility of the United States throughout the world. Is he wrong about that? (VIII)

Except for (11b), all the other questions formulate their topics by appeal to accusations made by Dole. In (11a) [and (4b)], Dole is not only the candidate whose accusations are the topics of the current question, he is also the initial respondent of Lehrer's question; in (11c) and (11d), the role of initial respondent to Dole's accusations is assigned to Clinton.

In (11b), Clinton is asked to clarify a prior remark of his own. Unlike the remarks of Dole's quoted in (11a, c-d), Clinton's quoted statement in (11b) typifies the election race by describing a series of choices-formulated by means of stacked parallelistic clauses —without explicitly mentioning his opponent. Although Clinton's remark has

\footnotetext{
${ }^{17}$ Note that, in all the examples in (11), Lehrer distinguishes the candidates' prior speech from his own by means of metapragmatic framing devices. In (11a) and (11b), the frame is the most denotationally explicit device available in English, the 'quote...unquote' construction; here the framing material formulates the framed material as identical to the 'original' speech event. Examples (11c) and (11d) are cases of indirect report where the framing material does not stipulate such identity in any kind of transparent way. Nonetheless, even here, Lehrer differentiates the most significant phrases in the framed material from his own report frame- and from the rest of the reported speech—by means of pitch alternations, e.g. ${ }^{\wedge-}$ lying $^{-\wedge}$ in $(11 \mathrm{c})$ and ${ }^{-}$photo op ${ }^{-\wedge}$ in $(11 \mathrm{~d})$.
} 
disparaging implications for Dole, it is not quotable as an accusation; its potential construal as an accusation is, in fact, the topic of Lehrer's yes-no question to Clinton himself. Moreover, throughout the debate, Lehrer never asks Dole any questions which require him to defend himself against accusations by Clinton.

Questions of both the first and the second type (i.e. about the 'issues', about prior speeches) share a common feature: They are all questions which are motivated by events which occurred before the debate began. They all have a pre-scripted quality in this sense. Yet even in the pre-scripted question about 'prior speech', Dole's prior speeches tend to set the agenda for the current debate much more heavily than Clinton's do.

Moreover, newspaper summaries of Lehrer's questions explicitly describe these first two types of questions well enough, even though they do not mention the relatively greater effectiveness of Dole's prior speeches in shaping the current debate:

\footnotetext{
'Most of the questions and answers tonight were based directly on key passages from the rivals' ads and speeches - an agenda that invited mini-debates on topics from school choice, drug policies, Medicare, taxes, campaign reform and crime to Somalia, the Persian Gulf and the Middle East. Republican officials complained after the debate that PBS anchor Jim Lehrer, the moderator, had not pressed Clinton on the administration's ethics record, but Dole himself seemed reluctant to go in this direction' (WP, X/7:A1)
}

\subsection{Dole's voice in Lehrer's questions}

Some of Lehrer's questions are of a distinct - third-type, however; the distinctive character of this third type is not mentioned in any of the newspaper accounts. Lehrer formulates the topic of this third type of question by appealing explicitly to utterances produced within the debate itself. There is one case where a prior remark of Clinton's is directed to Clinton $(\mathrm{C} / \mathrm{C})$ for clarification; one case, where a remark of Dole's is topical in a question to Dole (D/D). The other two logically possible cases show a marked asymmetry: Only once is a remark of Clinton's formulated as the topic of a question to Dole $(\mathrm{C} / \mathrm{D})$; but there are five occasions when a remark of Dole's becomes the topic of a question to Clinton (D/C). It should be clear that Dole's remarks within the debate itself (like his earlier speeches) set the agenda for Clinton's responses much more heavily than the other way around.

One example of this is Lehrer's appeal, in episode Va, to an earlier remark (of Dole's) in formulating the question (to Clinton) which initiates the episode. Let us consider Dole's earlier remark first. In episode IV, while describing his tax-cut proposal as a 'sixpoint package', Dole describes 'litigation reform' as one of the 'points' covered by the package. The remark about Clinton follows thereafter:

(13) Dole: ...It's about litigation reform. Now that the president gets millions of dollars from the trial lawyers, he probably doesn't like this provision... (episode IV)

Dole's remark is a thinly veiled accusation that Clinton is influenced by donations from trial lawyers in making his decisions. It is an accusation of influence to the extent that it implies a causal connection between donations by trial lawyers and Clinton's political opinions; it is veiled by a temporal ('Now that...') — rather than explicitly causal—-link 
between the two clauses, and by hedging ('probably') in the second clause. Lehrer alludes to this remark in formulating his very next question.

(14) Lehrer: Mr. President uh, the senator mentioned trial lawyers and camp- that means campaign financing. How do you personally avoid being unduly influenced by people who give you money or give you services in your campaigns? ( Va)

Dole utterance is not only reported in Lehrer's utterance ('the senator mentioned trial lawyers'), it explicitly motivates the topic of Lehrer's question to Clinton. After reporting Dole's remark, Lehrer glosses it himself ('that means campaign financing') and formulates a question to Clinton on this very topic. Although Lehrer is the animator of the question, Dole is the author of the reported material which motivates the question. Although Lehrer is the overt agent who asks the question, Dole's agency is translated through Lehrer's utterance in a pattern of 'voiced agency'.

\subsection{Additional examples of Dole's voiced agency}

A second example of Dole's voiced agency may be found in the transition from episode $\mathrm{Vb}$ to episode VI. In Vb, Lehrer re-directs the above question about campaign financing to Dole; in answering this question, Dole alludes to Clinton's prior drug use. Lehrer then asks Clinton explicitly about drug use. Dole's achievement is worth looking at in some detail.

In episode $\mathrm{Vb}$, while responding to Lehrer's prescribed topic (the campaign financing issue), Dole shifts the topic twice: First to Clinton's anti-smoking campaign, and then to Clinton's 'selective memory' about drug use. The first shift is achieved by means of an explicit re-framing of the topic:

(15) Dole:

...But I want to touch on this tobacco thing. I know the president's been ...(0.6 sec.)...puffing a lot on that. < gaze turns toward Clinton $>\ldots(\mathrm{Vb})$

The word 'puffing' is foregrounded phonetically by the prosodic break before it. Although the stem 'puff-' corresponds to at least three homonymous lexemes in English, its usage here clearly identifies it as the transitive verb used to describe smoking; the criterial contextual cue is the use of the word 'tobacco' in the preceding sentence. Secondly, although the best contextual candidate for the antecedent of 'that' is 'this tobacco thing', the gloss 'the president's been puffing a lot on [this tobacco thing]' is odd by strict lexicogrammatical criteria. Given this anomaly, the utterance calls attention to itself as defective in some way, permitting no clear literal interpretation. Third, in the context of smoking, the lexeme 'puff' implies 'not inhale', thus bringing into play one of the most widely quoted and controversial of Clinton's denials during his presidential career ('I didn't inhale'; Clinton's claim about his own marijuana usage during his years as an Oxford student); finally, the perfect progressive aspect in 'the president [ha]s been puffing' implies that Clinton has continued to 'puff' right up to the present. Five sentences later, Dole performs the second topic shift, shifting the topic from 'this tobacco thing' to 'drugs'. The new referential topic fits neatly with his earlier predicational allusion (i.e. 'puffing'): 
(16) Dole: $\quad$...What about drugs that have increased uh uh double in- in the last 44 months? Cocaine's up 141 percent- or, marijuana. Cocaine up 166 percent. I mean, it seems to me that $<$ gaze turns to Clinton, and stays there $>$ you have a selective memory. And a- m- y'know mine doesn't work that way, so I just want to try to correct it as we go along. (Vb)

Since Clinton has said nothing about drugs so far, Dole's use of drug statistics to motivate his claim that '[Clinton] ha[s] a selective memory', seems to be something of a nonsequitur, at least at the level of denotational text. At the level of tropic allusion, however, the link between Clinton and drug use has already been motivated, to a degree, by Dole's prior assertion. In introducing the explicit discussion of drugs in (16), Dole uses the metapragmatic frame 'I mean...', thus formulating his subsequent utterances as an explicit metapragmatic gloss on his previous utterances. The gloss, '...you have a selective memory', is produced in highly explicit direct address to Clinton. Now, '[Clinton's] selective memory' is itself a fairly direct allusion to a charge which has been made several times against Clinton (by Dole, by the press, etc.) in public discussion of scandal(s) involving drugs (and sex). Like descriptions of '[Clinton's] puffing', descriptions of '[Clinton's] selective memory' invoke drug use by stereotypic allusion. Both allusions are predicated of Clinton, thus converging referentially; both allusions overlap in the events to which they allude (i.e. drug use), thus motivating each other predicationally. Two properties of the trope linking Clinton and drug use are worth noting: (a) Dole has nowhere produced a segmentable ('quotable') sentence linking Clinton with drugs; (b) Dole has not made the nature of the link denotationally explicit. The non-congruence between explicit denotation and implicit allusion is precisely what yields the tropic effect.

One measure of the effectiveness of the trope is that Lehrer formulates his next explicit question by appeal to it; yet properties (a) and (b) become problems for Lehrer, forcing two repairs within his own question.

(17) Lehrer: Mr. President uh, the senator mentioned drugs. He's said- he's suggested in the past that you are- ...(1 sec.)... you bear some responsibility for the rise in drug use of teenagers in the United States. Is he right? (VI)

Since Dole's attempt to link Clinton with drug use is not segmentable as a sentenceproposition from any of Dole's preceding utterances, the initial matrix clause 'He's said' (with proposition-reporting matrix verb, 'say') quickly gives way to 'he suggested in the past' (with a verb used more easily to report allusions, 'suggest', and a vague reference to past time). Secondly, since Dole has not established any clear relationship between Clinton and rising drug use, Lehrer's next segment, 'you are-', immediately gives way to 'you bear some responsibility for...'. At the same time, in asking Clinton this question, Lehrer has converted Dole's allusions into the denotationally explicit formulation that '[Clinton] bear[s] some responsibility for the rise in drug use of teenagers in the United States', a proposition which Dole nowhere asserts within the debate, but which now forms the content of Lehrer's yes-no question to Clinton.

A third case where Dole's utterances motivate Lehrer's questions to Clinton involves the transition from episode XX to XXI. In episode XX, Dole concludes his turn as initial respondent with the summary statement in (18a); after Clinton's response, and Dole's rebuttal, Lehrer's next question, formulating the topic of episode XXI, is (18b): 
(18)

(a) Dole: ...People will tell you who served with Bob Dole that, agree or disagree, he kept his word That's what this race is all about. (XX)

(b) Lehrer: Mr. President, what do you say to Senator Dole's point that- that this election is about ${ }^{{ }^{\circ}-}$ keeping one's word ${ }^{-00}$ ? (XXI)

Dole's utterance, '[Dole] kept his word' is generalized in Lehrer's utterance to 'keeping one's word'; the generalization is formulated by changes in pronouns (his: One's) and verb inflection (past: Gerund), and is reported as Dole's 'point'; the slower tempo of 'oo-keeping one's word $^{-\mathrm{oo}}$ ' in Lehrer's question foregrounds the reformulated material.

A fourth case occurs in episode XVII. In responding to a question about his own earlier accusation - that Clinton's cabinet is filled with elitists (see (11a) above) - Dole introduces a new topic, namely that Clinton's cabinet consists of 'liberals'. These 'liberals', Dole implies, don't 'know the hard knocks in life' (implying, therefore, that their 'liberal'ism and 'elitism' are related). Clinton himself responds by equivocating on the question of his 'liberal'-ism. This development, initiated by Dole and ratified by Clinton, is followed by Lehrer formulating the following as the topic for episode XVIII:

(19) Lehrer: Mr. President, if you're not a liberal...(2 sec.)...describe your political philosophy.

The fifth case is again highly similar. In episode IX, Dole uses the occasion of Lehrer's question [about the criteria Dole would use to send U.S. troops abroad] to launch an attack on Clinton's troop deployments. Dole's final topic segment begins with a rhetorical question, followed by an answer: 'Here we have Cuba, 90 miles from our shores, and what have we done? We passed a law that gave people a right to sue, and the president postponed it for six months.' In continuing, Dole switches to direct address to Clinton, offering some advice: 'And it seemed to me if you want to send a signal, you've got to send a signal, Mr. President. The sooner, the better off we'll be, if you put tougher sanctions on Castro, not try to make it easier for him'. The very next utterance, preserving direct address as well as topical content from Dole's utterance to Clinton, is Lehrer's question to Clinton. This question formulates the topic for episode $\mathrm{X}$ :

(20) Lehrer: Mr. President, what is your attitude toward Cuba and how Cuba should be treated?

As opposed to these five cases, there is only one occasion where Lehrer's appeal to a remark of Clinton's sets the agenda for Dole's responses. This is the remark of Clinton's which is quoted by Lehrer in formulating the question to Dole in episode II; this instance is noted in (3a) above. Yet this single C/D case is quite unlike the five D/C cases already discussed. Although Clinton's remark does set the agenda for Dole's response, it does not occur in the immediately prior episode: The remark itself- 'We are better off today than we were four years ago'-is one which Clinton had formulated in his opening statement, eight speaking turns earlier; it is also one which Clinton had used many times in prior campaign speeches. Lehrer's appeal to it has some of the same pre-scripted quality as his appeal to the pre-debate quotes in (11) above. Moreover, like the quote from Clinton in (11b) above, the quote from Clinton in (3a) does not explicitly mention Dole. Dole therefore has a good deal of latitude in how he responds; he succeeds, in fact, in reversing 
the tables on Clinton immediately — as the audience's laughter in (3a) indicates — scoring what is perhaps his greatest rhetorical success in the debate.

The five cases where Dole's remarks set the agenda for Clinton are quite different. On all of these occasions, Dole formulates explicit descriptions of Clinton; and, in all of these cases, Lehrer appeals to these descriptions - and, in (19), to Clinton's contrastive responses to them as well - in formulating his very next question to Clinton. Dole uses a number of devices, such as explicit accusations of wrong doing (e.g. the claim about 'trial lawyers' in (13), quoted by Lehrer in (14)), tropic allusions to past misconduct (in (15)(16), made explicit by Lehrer in (17)), 'rhetorical' questions (as in the 'Cuba' example above) which motivate Lehrer's 'official' questions (in (20)), and so on.

When Lehrer asks Clinton questions of this - third - type, neither the overtly segmentable form of the questions, nor their pragmatic effects have the 'pre-scripted' character of questions of the first and second type. They are all cases where the form and content of Lehrer's questions to Clinton are influenced by immediately preceding remarks of Dole's. In influencing Lehrer in this way, of course, Dole succeeds in manipulating the sanctioned metapragmatic rules of the debate rules which stipulate that he cannot ask questions of Clinton.

\subsection{Newspaper coverage}

Unlike the pre-scripted questions (e.g. (10) and (11)), which are explicitly described in newspaper accounts (e.g. (12)), the questions of this third type are not explicitly described as such. In particular, the pattern of voiced agency which I have described goes unremarked. Several accounts do pick up on the more localized-i.e. turn internal-features of Dole remarks, as in the following example:

\footnotetext{
'Trailing in statewide and national polls, Mr. Dole was on the offensive throughout the 90 -minute program in Hartford, occasionally displaying a sharp edge, frequently flashing a dry wit and needling $\underline{\mathrm{Mr}}$. Clinton by calling him a liberal elitist who had done little to curb drug-use among teenagers and whose policies would saddle Americans with higher taxes' (NYT, X/7: A1; my emphases)
}

Most of the utterances of Dole's that I have cited above are good examples of 'needling Mr. Clinton'. It is worth noting, however, that Dole nowhere utters the words 'elitist' or 'liberal elitist' within the debate-let alone uses them to describe Clinton. Dole does call Clinton a 'liberal', and does so several times during the debate. Moreover, Dole has called Clinton an 'elitist' in the past, but this charge was formulated originally in Dole's speech at the Republican Convention. It is Lehrer who introduces the issue of 'elitism' into the debate - in question (11a) — explicitly quoting Dole's prior speech in doing so. Once Lehrer has introduced the issue of 'elitism' in question (11a), Dole proceeds to call Clinton a 'liberal' in responding to this question. It is perfectly accurate to say that Dole is the author of the charge that Clinton is 'a liberal elitist'; but Dole's authorship is mediated by Lehrer's (re-)animation of Dole's prior speeches.

Notice, then, that the newspaper report in (21) presupposes the pattern of 'voiced agency' in reporting its effects, but does not describe the pattern itself. Secondly, in reporting the effects of Dole's voiced agency, the newspaper account selects only locally segmentable and unavoidably referring pieces (i.e. the words 'liberal' and 'elitist') from 
an array of semiotic devices which are much less localizable (i.e. patterned across several turns) and which contain many non-referring elements. Similarly, the newspaper account attributes the remark that '[Clinton] had done little to curb drug-use among teenagers' to Dole. Actually, Dole never says this, as I have noted above. He makes two tropic allusions - noted in (15) and (16) above-which Lehrer converts into the localizable and denotationally explicit (and, now, easily 'reportable') proposition in (17)—i.e., '[Clinton] bears some responsibility for the rise in drug use of teenagers in the United States'. This utterance of Lehrer's bears a more transparent relationship to the newspaper quote in (21) than any utterance produced by Dole himself within the debate.

In both cases, therefore, the newspaper is reporting on charges which Dole has 'authored' but where Dole's authorship is mediated by Lehrer's utterances. Dole's utterances do describe Clinton, of course; but, in addition to their denotationally explicit content, Dole's utterances implement additional indexical effects which imply something about Clinton. This 'surplus' depends upon a non-congruence between explicit denotation and indexical allusion. All of these allusions are highly non-detachable for purposes of construal; they are effects which are not reportable once they are decontextualized from the co-textual frames in which they are produced. Dole's tropic allusions about Clinton become 'explicit' in Lehrer's utterances in the sense that they are denotationally segmentable in them, and are now transparently reportable, without appeal to any other feature of context. The newspaper reports do not describe the pattern of 'voiced agency'; but they presuppose it in attributing descriptions - which are, in fact, co-constructed by Dole and Lehrer-solely to Dole. To this extent, the trope of Dole's 'voiced agency' is quite construable by these reporters, even though it is not explicitly described, as such.

\section{Implicit breaches: Metapragmatic-pragmatic incongruity in Dole's speech}

In the cases I have discussed in the previous section, the interactional effectiveness of Dole's utterances consists in the fact that his utterances successfully implement implicit other-typifications - typifications whose indexical focus is, in particular, Clinton. These utterances work to Dole's advantage in these cases. I now turn to examples where Dole's utterances implement implicit typifications (of both self and other) which reflect badly on Dole himself. We have already seen an example of this in (7) - judged 'harsh' by the newspaper report in (8) - but there are several other examples as well.

\subsection{Internally inconsistent denials}

On a number of occasions, Dole produces utterances which describe the pragmatic effects of his own utterances - but do so incorrectly. These utterances have first person pronouns as grammatical subjects, and negated verba dicendi as predicates. In these cases, Dole's utterances formulate explicit metapragmatic descriptions of his own utterances; but these explicit descriptions-which are always denials - are inconsistent with the implicit pragmatic effects of his utterances.

In the example in (22), Dole immediately spots the infelicity and attempts a repair. 
(22) Dole:

...I'm not some extremist out here. I care about people. I have my own little foundation that's raised about 10 million dollars for the disabled. I don’t ${ }^{\wedge-}$ advertise $\underline{i t}^{-\wedge}-$ just $\underline{\text { did, }}$ haven't before. And I try to do a lot of things that I think might be helpful to people... (XV)

Simply by virtue of the fact that he is describing his charitable deeds before millions ofviewers, Dole is implicitly 'advertising' them - even in the narrow sense of television advertisement. In this setting, mere description counts implicitly as 'advertising'. Even if Dole's claim ('I don't advertise it') is otherwise true (e.g., in its habitual sense), its current pragmatic context makes it untrue here.

Several cases of Dole's metapragmatic-pragmatic inconsistency involve Clinton as well, whether through explicit denotation or by stereotypic allusion. In these cases, these utterances are not just self-inconsistent, they have disparaging implications for Clinton.

The example in (23) exhibits this pattern in a case of stereotypic allusion. Dole's utterance occurs in his final 'rebuttal' turn in episode XIXa; the official topic is 'personal differences'.

(23) Dole:

\begin{abstract}
...And getting back to personal differences. I- I don't- you know- I think- if Jim, if you're a little more specific. But I- I think the president c-could clarify one thing tonight and that's the question of pardons...(2 sec.)... I know you talked about it on the Jim- the Jim Lehrer- on the PBS show. And I've never discussed Whitewater, < gaze turns to Clinton> as I've told you personally. I'm not discussing Whitewater now. But I am discussing a power the president has to grant pardons. And, hopefully, in the next segment you could...(1 sec.)...lay that to rest. (XIXa)
\end{abstract}

Here, the denotational incongruity of the formulation 'I'm not discussing [...] now' frames the mention of 'Whitewater'. Hence, although Dole claims at the end of episode XIXa that he is really discussing the 'power the president has to grant pardons', his mention of 'Whitewater' alludes to Clinton's involvement in illegal activities. This is a point which Clinton explicitly addresses in his first turn as 'initial respondent' of episode XIXb. This is a tropic departure from the official rules of the debate in the following sense: Clinton is not supposed to answer Dole's questions, but he does.

\title{
9.2. Lamination of tropes: Inconsistent denials in the service of voiced agency
}

Clinton's response to Dole's achievement in episode XIXa is mediated by the question which Lehrer uses to assign the role of 'initial respondent' to Clinton in XIXb. This is the most peculiar question in the debate, though its peculiarity is not evident from its surface form. Here is Lehrer's question:

(24) Lehrer:

Mr. President? (XIXb)

Lehrer's question (which is supposed to introduce an explicit topic for Clinton's comment) is identical in form to his 'transitional questions' (see note 10), and has the (near) zero denotational content typical of them. Episode XIXb is unique in the debate in that the question which initiates it is, in fact, a type of question which Lehrer uses elsewhere only 
to re-allocate turns within episodes. (Indeed, XIXb is isolable as a separate 'episode' only by the criterion that the 'initial respondent' is rotated across episodes: Dole is the IR in episode XIXa, Clinton in XIXb, and Dole again in XX) ${ }^{18}$.

Lehrer's question in (24), 'Mr. President?', may well be an attempt by Lehrer to pose his own earlier question about 'personal differences' [addressed originally to Dole, episode XIXa] in a re-directed form to Clinton [in XIXb]; however, Lehrer's intentions are far from clear. The question which Clinton actually answers is, in any case, the question about pardons which Dole has posed in (23): 'I am discussing a power that the president has to grant pardons. And, hopefully in the next segment you could...lay that to rest'. The fact that Clinton uses up one of his turns as 'initial respondent' in answering a question formulated explicitly by Dole here indicates a much more powerful instance of Dole's 'voiced agency' than any of the preceding cases: Lehrer's intervening question in (24) vanishes to a zero, making no additional contribution-no semantic reformulation of topic, no pragmatic softening of Dole's allusions - in formulating Clinton as 'initial respondent' to Dole's request for clarification.

Clinton's answer is reproduced in (25), with two initial sentences omitted. The omitted sentences refer to Clinton's recent contact with Senator D'Amato in connection with the Whitewater issue.

(25) Clinton:

\begin{abstract}
... Let me say what I've said already about this pardon issue. This is an issue they brought up. Thi- It's under- there's been no consideration of it, no discussion of it. I'll tell you this: I will not give anyone special treatment, and I will strictly adhere to the law. And that is what every president has done, as far as I knów in the past. But whatever the other

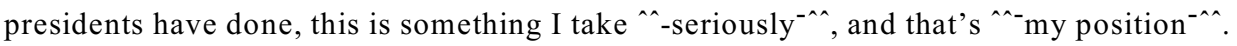
(XIXb)
\end{abstract}

Clinton's response is marked by two instances of infelicity and repair, very rare in his speech elsewhere in the debate; he appeals first to the mantle of the presidency, then distances himself from this appeal, describing the issue as something which he-in particular - takes 'seriously', re-framing his remarks, utterance-finally, as 'my position'; both of these phrases are marked by higher pitch than the surrounding material. It is evident here that Clinton feels the pressure, quite keenly, of Dole's tropic achievement.

\title{
9.3. Dole's inconsistent denials and their reception
}

I return now to the issue of metapragmatic-pragmatic incongruity in Dole's speech. In the following example, Dole exhibits this characteristic pattern of incongruity in suggesting that Clinton is unsure about his own policies.

(26) Dole:

... I mean, you take a look at all the programs you've advocated, Mr. President.
Thank goodness we had a Republican Congress there. ${ }^{»-}$ The first thing you did when you

${ }^{18}$ Episode XIXb is also the most internally disrupted episode in the debate. It does have the four part structure noted in (2), but this structure is fragmented by the lack of an explicit question [cf. (2.i)]; by Clinton's speaking out of turn during Dole's 'rebuttal' [cf. (2.iii); Clinton's utterance is shown in (3d)]; and by Dole's speaking out of turn during Clinton's 'response' [cf. (2.iv); Dole's utterances is shown in (31)]. 


\begin{abstract}
came into office-» was send up a stimulus package. Said: 'We've got a little pork we want to scatter around America, 16 billion dollars.' And even some in your ówn party couldn't buy thát. I remember talking ((t'you)) by the telephone. I'm not even certain yóu were too excited about it. I won't- I never- repeat what I've talked to the president about, but-. In any event, we saved the taxpayers 16 billion dollars... (XVII)
\end{abstract}

So, after describing the lack of support by other Democrats, Dole has mentioned here a telephone conversation with Clinton, and then added: 'I'm not even certain yóu were too excited about it'. In effect, Dole has explicitly described Clinton as unenthusiastic about his own 'stimulus package' during their phone conversation. In this context, the metapragmatic typification of Clinton's lack of enthusiasm has a clear pragmatic entailment: Clinton's proposals not only lack the support of other Democrats, they lack even his own support. The subsequent self-typification 'I won't- I never- repeat what I've talked to the president about...' is markedly at odds with what Dole has just done. The incongruity is evident, even though it is not legally consequential: Dole has not described the denotational content of his conversation with Clinton. Yet, he has described its pragmatics, and this description is disparaging towards Clinton.

The example in (27) is like the case in (24); here, the metapragmatic-pragmatic inconsistency in Dole's utterances forces a response from Clinton.

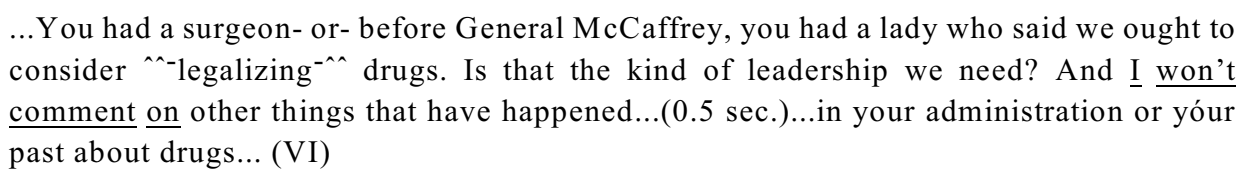
consider ${ }^{\wedge}$-legalizing ${ }^{-\wedge}$ drugs. Is that the kind of leadership we need? And I won't comment on other things that have happened...( $0.5 \mathrm{sec}$.$) ...in your administration or yóur$ past about drugs... (VI)

Here, Dole claims that he 'won't comment on' certain 'things that have happened...about drugs'. Of course, in doing so, Dole has commented that such things have happened; and he has described such 'things' in sufficiently explicit other-typifying detail (i.e. 'in your administration or yóur past') that Clinton is forced, in his immediately following turn, to offer the following explanation:

(28) Clinton: $\quad$...But let me remind you that my family has suffered from drug abuse. I know what it's like to see somebody you love nearly lose their lives, and I hate drugs, Senator. We need to do this together, and we can. (VI)

Once again, Dole's metapragmatic allusions are highly effective as interactional tropes. By alluding to Clinton's links with drugs, Dole forces Clinton to describe such links.

Although all four of Dole's utterances discussed above (i.e. (22), (23), (26) and (27)) are cases of metapragmatic-pragmatic infelicity, the cases in (23) ('Whitewater') and (27) ('drugs') differ from the other two cases in an important respect: Dole's allusions in (23) and (27) force Clinton to respond with explicit descriptions of himself ('I will strictly adhere to the law', etc., in (25), and 'my family has suffered from drug abuse' in (28), respectively). In these cases, Dole's implicit allusions are converted into denotationally explicit formulations by Clinton himself; here, Lehrer plays no internuncial role.

This difference of denotational transparency correlates with differences in newspaper reportage: The cases in (22) and (26) are not reported in any of the national papers; on the other hand, the 'Whitewater' and 'drugs' cases in (23) and (27) are reported by several newspapers. Of course, we might say that the cases in (23) and (27) are the more 
juicy cases because they are cases of one candidate attacking another; but this is true of (26) as well. But a clear distinction between the two cases which are reported and the two cases which are not, is that the former two are denotationally explicit cases of 'of one candidate attacking another': Despite the implicit and veiled qualities of the tropes which initiate them, the two textual developments which are, in fact, reported are just the ones which are made denotationally explicit by the semiotic work done by several interlocutors across turns (cf. (27)-(28), and (23)-(24)-(25)); and, in both cases, their denotational point becomes locally segmentable in the utterances of the one attacked (i.e. (28), (25)).

In (29), I list some of the reports of the 'Whitewater' and 'drugs' cases of (23) and (27). Some of these reports describe the tropic formulation (sometimes twice, in different stories on the same newspaper page, cf. (29c) and (29d)); some describe the tropic effect, e.g. (29e); and some do all of these things at once, drawing political lessons from the trope, e.g. (29f).

(a) 'Mr. Dole soon became personal, notably when he said he wouldn't mention Mr. Clinton's own experience with drugs. (Does that count as a mention?)' (NYT, X/7:B7)

(b) '[Dole] said he would not bring up any issue of the president's youthful drug use, which he did' (CT, $\mathrm{X} / 7$ : back page)

(c) '[Dole] raised the Whitewater issue while saying he would adhere to his policy of not raising Whitewater' (NYT, X/7: B7)

(d) 'As Mr. Dole peppered the President with quick, sharp critiques, the closest Mr. Clinton came to chasing a goading invitation was when Mr. Dole, while saying he would not bring up Whitewater, brought it up by asking whether Mr. Clinton might pardon some of those convicted thus far in Whitewater-related trials in Arkansas' (NYT, X/7: B7)

(e) 'Dole made two brief mentions of the Whitewater real estate matter, and did not mention others at all...The hardest punch that Dole threw was to ask why Clinton would publicly consider pardoning a convicted criminal with whom he had business dealings' (CSM, X/8: 8)

(f) 'Given an opening to discuss "personal" issues by the moderator, Mr. Dole at first demurred and than looped back to take a half-hearted stab at the question of Whitewater pardons. "I've never discussed Whitewater...I'm not discussing Whitewater now. But I am discussing...pardons," he said before letting Mr. Clinton off the hook. By referring to the scandals so vaguely, he probably helped the President sell his line that there was nothing to the investigations except innuendo.' (NYT, X/7: A16, Op. Ed.)

\section{Repossessing the other's words}

On a number of occasions, each candidate attempts to repossess the other's utterances, reformulating what the other has said to suit himself. The number of instances is very large - and quite various in the semiotic-metasemiotic relationships employed. The two cases I have selected for discussion here are both linked - by topic - to the developments in (23)-(25) described above.

Recall that, in (23), Dole has alluded to Clinton's involvement in Whitewater and asked for a clarification about 'pardons' from Clinton; in (24), Lehrer has allocated a turn to Clinton, directing Dole's request to him; in responding in (25), Clinton has appealed to the mantle of the presidency, then distanced himself from this appeal in formulating his own 'position' on pardons. After this sequence, Dole responds in his next turn as follows: 
(30) Dole: $\quad$ But it seems to me the president shouldn't have any comment at all. Particularly where it's someone where you've had bealit- business dealings, I mean you may be sending a signal. I don't know. I'm not questioning anybody. But as the president of the United States, when somebody asks you about pardons, you say: 'No comment.' Period. And I think he made a mistake. And I think uh when you make a mistake, you say: 'I made a mistake.' Butapparently his position hasn't changed... (XIXb)

Here Dole criticizes Clinton's remarks, proposing that an appropriate response by the 'president of the United States' (to a question like the one which Dole himself has raised) should be 'No comment'. Dole is now describing how Clinton should speak. Dole then describes Clinton's actual response as a 'mistake', spelling out the actual sentence which Clinton should use in admitting the mistake. After some intervening material-including the exchange in (3d) above-Lehrer re-directs to Clinton, thus giving Clinton an opportunity to respond to Dole in the final official turn of episode XIXb; Dole's subsequent remark is an out-of-turn utterance.

Lehrer: Mr. President, 30 seconds

Clinton: No comment.

[loud laughter, then applause

Dole: What's the subject matter?

\{mild laughter\}

Clinton's two-word response, 'No comment', reproduces the very words which Dole has personified as appropriate to 'the president'. In uttering these two words here, Clinton fully inhabits the presidential persona which Dole has linked with these words, using it effectively against Dole himself: The audience's laughter and applause is loud and prolonged. In this context, Dole's utterance in (31) appears rather defensive; it lacks all of the characteristic features of his out-of-turn utterances elsewhere in the debate (cf. (4)ff.). Although the 'official' topic of the episode may well be 'personal differences' between the two candidates, Clinton's remark - which nowhere describes Dole - appears to have the tropic effect that its 'subject matter' is, now, Dole.

\section{Co(n)textual superposition and the construal of action}

To interpret a pragmatic act is, by definition, to formulate a metapragmatic judgment about its co(n)textualized effects. Recognizably tropic acts are special only in the sense that they motivate more than one metapragmatic judgment. This kind of fractionation of pragmatic effects poses a fundamental challenge to some of our most cherished folk-theories about language and action. The hardest hit, perhaps, is the folk-theory that pragmatic events are like words; that they have a unitary 'meaning'; that their meaning effects conventionally inhere in them. The possibility of tropes suggests that the interpretation of action works in an altogether different way: That the conventional properties of semiotic devices are invoked concurrently when these devices co-occur as text; that the effects of particular semiotic devices project emergent frameworks for construing the effects of others; that the interpretation of an act depends upon the co(n)textual superposition of independent, 
concurrently unfolding, pragmatic effects.

Even 'ordinary' utterance-acts - ones which are not recognizably tropic - call attention to the importance of co(n)textual superposition: When an 'ordinary' utterance is deco(n)textualized-whether for purposes of everyday construal, or for pragmatic analysis - some of its pragmatic 'meaning' appears inevitably to evaporate.

But recognizably tropic utterances do differ from seemingly 'ordinary' utterances in one important respect. The felt peculiarity of 'tropic' utterances draws our attention to the occasion of its performance in a special way, requiring us to process the co(n)textually superposed effects which are unfolding concurrently, and to process themwhile the utterances are still in play. Or, this is what we do, at least, when we are successful in proceeding from the recognition of a tropic formulation to its contextually appropriate construal. To recognize a 'tropic formulation' is to recognize that a given utterance-event brings into play co(n)textually significant effects which are distinguishable from each other precisely because they are inconsistent, or non-congruent, with each other ${ }^{19}$. The construal of the trope requires us to reject some of these effects, while maximizing the degree of congruence establishable for the rest.

In the preceding discussion, I have discussed numerous cases of tropic inconsistency where inconsistent effects are ranked in native metapragmatic judgments as follows: Denotationally explicit effects are more consistently reported in native speaker testimony than are implicit effects. In the present section, I want to review some of these cases from the point of view of the question of co(n)textual superposition. I focus only on two issues here: (i) the identifiability of the origo (or source) vs. the focus (or target) of aggression; (ii) the role of explicit description vs. implicit text structure in the identification of origo and focus.

I consider, first, two cases-(3a) and (5) - here Clinton produces self-typifying statements. In the first case, Clinton's self-typifications count co(n)textually as selfdefensive acts, locating him as the focus of aggression; in the second case, Clinton's selftypification have other-coercive effects. In (3a), Clinton's self-typifying statement ('I agree with that. That's right') occurs under the following co(n)textual conditions, as we noted above: Clinton has just been the topic of Dole's description ('Well, hé's better off than he was four years ago'), one which is disparaging towards Clinton; and, members of the audience laugh at Dole's remark, and continue to laugh during Clinton's response. These cues jointly motivate a superimposed construal: Dole is on the attack, Clinton is on the defensive. Moreover, Dole's utterance is reportable as aggressive because its disparaging content is denotationally explicit to a high degree. Under these conditions, Clinton's selfdescription is recognizable as an instance of self-defensive behavior, whatever else it may also be an instance of.

19 All 'deviationist' theories of metaphor misconstrue the nature of this internal fractionation (of concurrent semiotic effects) in favor of the idea that the utterance-act itself, as a whole, 'deviates' from some external standard. Yet utterance-transcendant standards, such as the Gricean maxims (see note 3 above), are not manifest in the data. Indeed the relevance of the Gricean maxims to the data of tropes is precisely that the data is a deviation from them, or that the maxims are 'violated' in it. Such maxims therefore have the ironic fate that they must, by stipulation, be universal, but that they do their greatest 'explanatory' work precisely when they are not manifest in the data! There is no sense in trying to 'disprove' this approach, since nothing can really count as empirical evidence against it. Yet a better attention to the data of utterances might yet afford us a cure. 
In (5), Clinton offers several self-typifications ('I want to begin...', 'I respect...', 'I will try...', etc.) which describe his own actions; however, his self-descriptions have implications for Dole, who is his interlocutor in 'this debate' (see (6)ff.). In press coverage, Clinton's utterance is reported explicitly as a "compliment' and as 'a statement of "respect" for Dole', even though the press report describes its implicit coercive effects as well: "...Dole did not offer a return compliment, but he treated the "character issue," which many Republicans regard as Clinton's greatest vulnerability, with great circumspection' (X/7/96:A1). To the native speaker who offers this description (i.e. the journalist), Clinton appears effectively to have coerced Dole into behaving in a certain way; yet Clinton is identified as the origo of a compliment, not of any act of aggression. Indeed, Clinton is not straightforwardly reportable as aggressor simply because the effectiveness of the trope depends upon implicit textual patterning; no denotational segment of the text structure in (5) implements any disparaging descriptions of Dole.

Let us consider a second issue, the issue of text structure in general, and of parallelism in particular. Like Clinton's speech, Dole's speech is often marked by parallelism, but the parallelistic trope which he employs most frequently is the one termed 'antithesis' in traditional rhetoric. The trope consists of a layered series of denotational contrasts. In (7), for example, Dole's utterance implements contrasts between subject nouns ('I': 'You'), time reference (present : Past ), reported addressee ('you': 'President Bush'), and address forms ('Mr. President': '[not] that'); moreover, the first (self-typifying) proposition of the antithesis frames the second (other-typifying) proposition as disparaging towards Clinton ('[Dole] wíll address [Clinton] as Mr. President. [Clinton] didn't do that with [Bush] in 1992.'). A second token of this trope-which I have discussed in (9)ff. above - embeds this denotationally transparent antithesis in a larger textual frame which motivates a series of stacked antitheses: (i) Dole respects Clinton, Clinton disrespects Bush; (ii) Dole respects the presidency, Clinton does not; (iii) Dole 'keeps his word', Clinton does not; (iv) Dole's campaign is based on 'trust', Clinton's on 'fear'. The first and the fourth of these antitheses are denotationally transparent in Dole's utterances, as I have noted above. The textually cumulative effect is reported as involving 'harshness'; yet Dole's description of his respectful address to Clinton mitigates the harshness in a way transparent to the native speaker who formulates the following report: 'That was why [Dole] was so careful to keep harshness to a minimum and to remind Clinton he was referring to him as "Mr. President," something he said Clinton had not done with George Bush four years ago - although he [=Dole] did it one too many times.' (WP, X/7: A7).

Clinton uses antithesis as a rhetorical device as well, but his antitheses do not describe Dole; they are denotationally implicit vis-à-vis Dole. The utterance of Clinton's which is quoted - from Clinton's Chicago speech - by Lehrer in (11b) is a good example of rhetorical antithesis. But here the implications of Clinton's remarks for Dole are sufficiently non-explicit that they become part of a request for clarification: Clinton's utterance is not reported as aggressive towards Dole; yet its potentially aggressive effects are, nonetheless, inferrable by Lehrer, and are made explicit in his yes-no question ('Are you saying that you believe Senator Dole is a man of the past...').

The cases of 'voiced agency' that I have discussed above in (13)-(20) are cases where Dole's remarks about Clinton help shape Lehrer's questions to Clinton. In some of these cases, Dole's remarks are fairly explicit in their disparagement of Clinton (e.g., (13)); in other cases, their disparaging implications for Clinton are tropically veiled to a higher 
degree (e.g., (15-16)). Lehrer becomes an instrument of Dole's voiced agency only in the sense that he re-directs the implications of Dole's remarks to Clinton in asking Clinton to respond. In doing so, Lehrer allows Dole to get around the 'official' rules of the debate, rules which he himself has explicitly described earlier (cf. (1)). Since the norms that are here implicitly violated are peculiar to the debate itself - they are not norms of ordinary discursive interaction - the fact that any norms have been violated at all is not transparent to native speakers of English. Showing that any norms have been violated at all requires attending to the lack of fit between local phases of the debate and the official rules which are supposed to be upheld globally throughout.

Moreover, there is nothing aggressive about Lehrer's own questions to Clinton. The very fact that Lehrer gives Clinton an opportunity to respond to Dole's allegations suggests that Lehrer is moved by considerations of fair play. Yet, whatever Lehrer's motivations may be, Lehrer does allow Dole to formulate the topics of questions which Clinton must answer. These cases are not transparently reportable as instances of aggression because no-one is transparently identifiable as an origo of aggression. Yet Clinton exhibits a degree of discomfort in his responses. He responds as if he were the focus of aggression. Finally, as I have noted in (21)ff. above, when the overall effects of these-multi-turn, textually global-discursive achievements are reported in newspaper accounts, these reports presuppose the pattern of voiced agency in formulating the report, without describing the pattern itself.

\section{Conclusion}

One implication of this study is that the notional vocabulary which we employ as native speakers of English in describing pragmatic acts - a vernacular terminology which includes words like 'aggression', 'coercion', 'harshness', 'politeness', etc.- is a vocabulary whose descriptive appropriateness for particular linguistic acts is mediated by rather general principles of the metapragmatic transparency of language form. In our most dominant folktheories of action, we tend to think of these words as simple labels for acts. The folk-theory is motivated partly by the fact that we often use these words as labels. But such words serve most effectively as labels for acts when these acts have already occurred. While these acts are occurring, however, the question of 'what is happening' remains a much more open question, simply because it can only by answered by attending to multiple concurrently unfolding semiotic effects whose emergent alignment gives to every candidate answer such cumulative shape as it has.

Cases of 'tropic' aggression are interesting in this regard because they motivate more than one answer to this question. Within the debate, the way in which interlocutors respond implicitly to each other's acts reflects a sensitivity to a much wider range of semiotic variables than those reflected in explicit reports by commentators. Explicit reports focus more selectively on referential, segmental and presupposing features of utterance form. Dole's utterances are reported as 'aggressive' whereas Clinton's are not because Dole's utterances are consistently aggressive along semiotic dimensions which are most easily reportable. On the other hand, Dole implements a pattern of voiced agency throughout the debate which is certainly coercive in its effects, but which is not reported as aggression. Clinton shapes audience and interlocutors responses through politeness, wide 
smiles, and jokes, e.g. (31). There are many more instances of this kind in the debate, though I have not discussed them here, partly for limitations of space, but mainly because these instances are neither reportable nor reported as 'aggression'.

These issues are of some general interest in the study of political language, particularly in our society where political language is experienced as the re-circulation of messages on a large social scale. They are relevant to our understanding of how political 'issues', as well as the personas of political candidates, are formulated, reported, and discussed by the public. The national media plays a role at every stage of this chain of speech-events, re-circulating public opinion in further reportage. I close with an example of a report which explicitly describes the ironic relationship of the debate to one occasion of its reception. The report calls attention to several implicit ironies as well-involving debating, voting, and the formulation of opinion — in a political life shaped by such reports:

\footnotetext{
'The Washington Post invited eight debaters from Georgetown [University], Clinton's alma mater, to watch the debate and offer their opinions, both as student debaters and as young people preparing to cast their first vote for president. The students, as members of Georgetown's Philodemic Debate Society, gather to debate every week as one of their passions in life. Four of the eight came into the debate undecided about how to vote. Two of those left still undecided, and two others left leaning toward Dole. From a debate standpoint, the students said, Clinton undoubtedly did better. By the standards of a debate society, "there's no doubt that Clinton wins every single time," said junior Cain Pence Jr., who plans to vote for Dole'. (WP, X/7: A6)
}

\section{Appendix}

Symbols used in the transcription:

Superscripted symbols are used to bound off material differing in pitch or tempo from surrounding material. These differences are marked as follows: Overhigh pitch $\left(\wedge^{\left.\wedge-{ }^{-\wedge}\right)}\right.$, overfast tempo $\left({ }^{\prime-}-{ }^{-»}\right)$, overslow tempo $\left({ }^{\text {oo- }}{ }^{-\mathrm{oo}}\right)$. Gestures accompanying the interlocutors' speech are contained within angular brackets, $<>$; these are intercalated with utterances, showing approximate relative position. Audience laughter and applause are shown within curly brackets, in a column separate from interlocutor speech, with rough indication of duration relative to speech, e.g., \{laughter----------\}; see note 12 for more details. Quotation marks (' ') and colons (:) are used to represent reported speech. Double parentheses, (( )), indicate barely audible material.

At the beginning or end of utterances, ellipsis (...) marks material omitted from the same turn; medially, it marks silence, with duration indicated in parentheses, e.g., ...(1 sec.)...; short pauses or prosodic breaks are marked with commas (,); accent (') on a syllable marks emphatic or contrastive stress; arrows $(->)$ are used to highlight turns, underlining to highlight utterance segments within turns. Equal signs $(=)$ indicate latching across turns.

\section{References}

Bauman, Richard \& Charles Briggs (1990) Poetics and performance as critical perspectives on language and social life. Annual Review of Anthropology 19: 59-88.

Ervin-Tripp, Susan (1976) Is Sybil there? The structure of some American English directives. Language in Society 5: 25-66.

Goffman, Erving (1981) Footing. In Forms of Talk. Philadelphia: University of Pennsylvania Press, pp. 124159. 
Putnam, Hilary (1975) The meaning of “meaning”. In Philosophical Papers, vol. 2: Mind, Language and Reality . Cambridge: Cambridge University Press, pp. 215-271.

Ricoeur, Paul (1979) The Rule of Metaphor. Toronto: University of Toronto Press

Silverstein, Michael (1981) The limits of awareness. Sociolinguistic Working Paper, no. 84. Austin, TX.: Southwest Educational Development Laboratory. 